Portland State University

PDXScholar

1977

\title{
Involvement of Hemerythrin Sulfhydryl Groups in Heavy Atom Binding and Subunit Interactions
}

Suzanne Elizabeth Clarke

Portland State University

Follow this and additional works at: https://pdxscholar.library.pdx.edu/open_access_etds

Part of the Chemistry Commons

Let us know how access to this document benefits you.

Recommended Citation

Clarke, Suzanne Elizabeth, "Involvement of Hemerythrin Sulfhydryl Groups in Heavy Atom Binding and Subunit Interactions" (1977). Dissertations and Theses. Paper 2473.

https://doi.org/10.15760/etd.2470

This Thesis is brought to you for free and open access. It has been accepted for inclusion in Dissertations and Theses by an authorized administrator of PDXScholar. Please contact us if we can make this document more accessible: pdxscholar@pdx.edu. 
AN ABSTRACT OF THE THESIS OF Suzanne Elizabeth Clarke for the Master of Science in Chemistry presented December 2, 1977.

TITLE: Involvement of Hemerythrin Sulfhydryl Groups in Heavy Atom Binding and Subunit Interactions

APPROVED BY MEMBERS OF THE THESIS COMMITTEE:

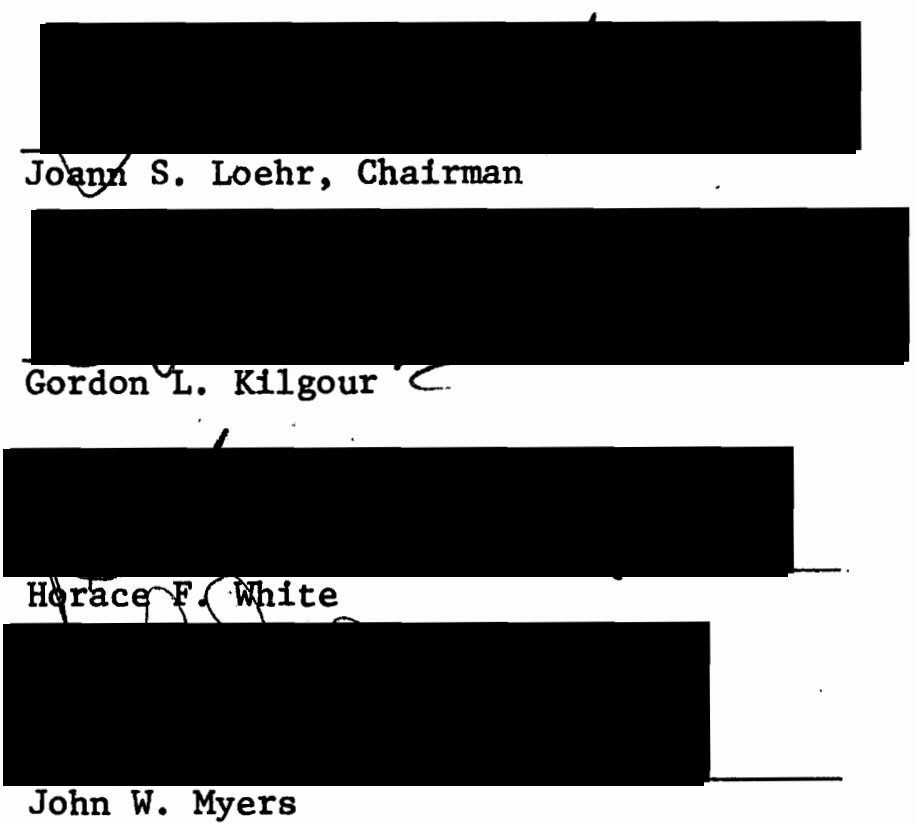

Hemerythrin is a respiratory protein found in the erythrocytes of certain marine invertebrates. Structures have been obtained by x-ray crystallography for hemerythrins from Phascolopsis gouldii (P. gouldii) and Themiste dyscritum (T. dyscritum). Upon solving the crystal structure of $\underline{T}$. dyscritum hemerythrin at 2.8 A resolution, two mercury binding sites were observed in the heavy atom derivative prepared by treating the protein with mercuric iodide. Since many proteins are inactivated upon binding heavy metals such as mercury, an 
investigation of mercury-proteln interactions in this protein was undertaken. In order to understand the nature of heavy-metal protein interactions in $\underline{T}$. dyscritum it was necessary to identify the metalloprotein ligands since neither the liganding amino acid restdues nor the geometry of the mercury complexes could be identified in the crystallographic studies.

Once the amino acid sequence of $\underline{T}$. dyscritum hemerythrin was determined, it was clear that both mercury binding sites were close to the thiol groups of two cysteine residues (cysteine 9 and cysteine 50). Possible structures for the mercury binding sites were identified by combining a knowledge of hemerythrin structure with direct evidence for mercury-thiol bond formation obtained by spectrophotometric titration of the thiol groups with mercuric iodide. The titration data showed that 1.5 atoms of mercury were bound per subunit, which is consistent with one mercury bound at cysteine 50 and one mercury shared by cysteine 9's of adjacent subunits. The mercuric lodide binding at cysteine 50 appears to be a linear structure (Protein-S-Hg-I), while the mercury bridging two cysteine $9^{\prime} s$ on adjacent subunits is better explained by a tetrahedral structure [(Protein-S) ${ }_{2} \mathrm{HgI}_{2}$ ]. The relative reaction rates of the thiol groups in hemerythrin with p-hydroxymercuribenzoate (PEMB) and N-ethylmaleimide (NEM) were investigated in order to gain information about the comparative hydrophobicity of the environments surrounding the two cysteines. The data showed the environment about cysteine 50 to. be hydrophobic relative to the environment about cysteine 9. This was substantiated by structural information which showed cysteine 50 to be buried in a subunit interface while cysteine 9 was in a region relatively exposed 
to the solvent.

Using the 2.8 resolution, computer-averaged electron density map for T. dyscritum hemerythrin provided by R. E. Stenkamp, L. C. Sieker and L. H. Jensen at the University of Washington, we were able to identify the amino acids responsible for the subunit interactions stabilizing the maintenance of the octameric ensemble. Most of the amino acids which appear to be responsible for the interactions are clustered in a region of the molecule near cysteine 50. This explains why octameric hemerythrin dissociates when it is treated with sulfhydryl reagents such as NEM, PHMB or salyrganic acid. However, dissociation appears to be a function of the bulkiness of the reagent used to modify cysteine 50 since the protein is not dissociated upon binding smaller molecules such as mercuric iodide. 
INVOLVEMENT OF HEMERYTHRIN SULFHYDRYL GROUPS IN HEAVY ATOM BINDING AND SUBUNIT INTERACTIONS

by

SUZANNE ELIZABETH CLARKE

A thesis submitted in partial fulfillment of the requirements for the degree of

MASTER OF SCIENCE

. in

CHEMISTRY

Portland State University

1977 
TO THE OFFICE OF GRADUATE STUDIES AND RESEARCH

The members of the Committee approve the thesis of Suzanne Elizabeth Clarke presented December 2, 1977.
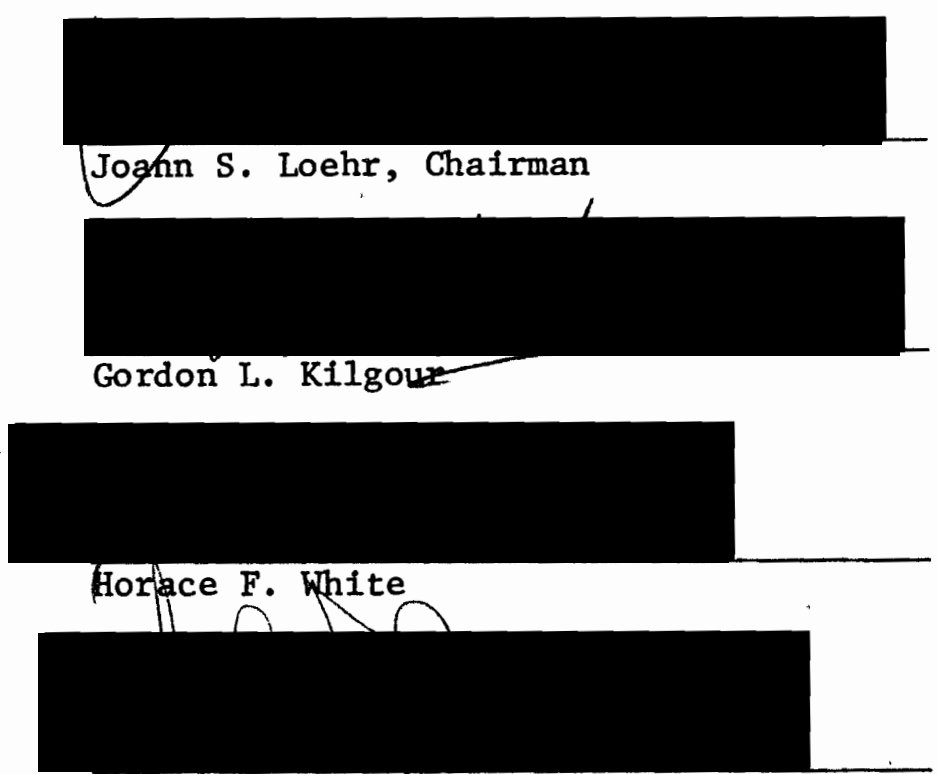

John W. Myers

APPROVED:
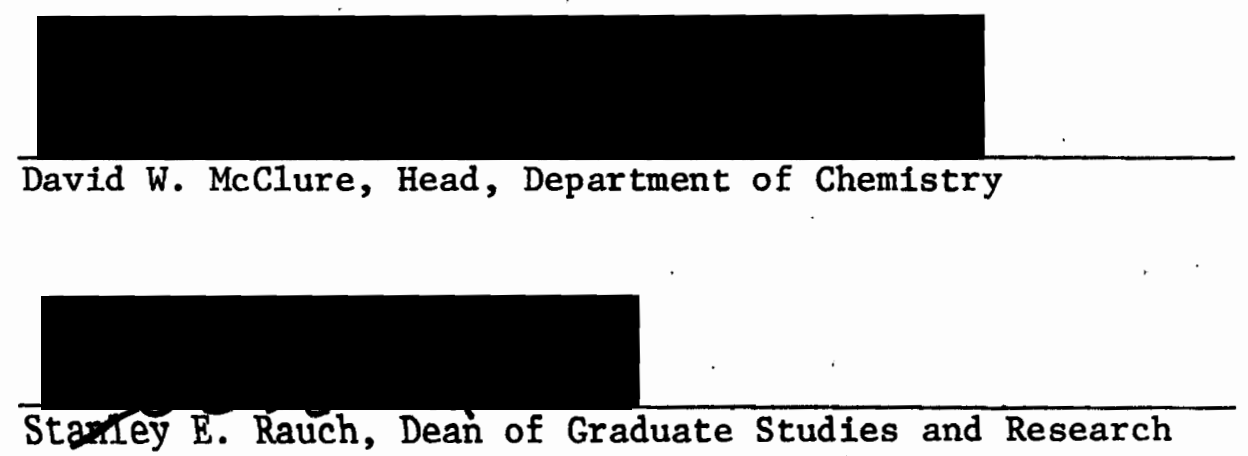


\section{ACKNOWLEDGEMENTS}

I am deeply grateful to Dr. Joann Loehr, who by setting high standards for herself teaches through example. I feel privileged to have had such an excellent research experience and feel that no other person has had a more positive influence on my scientific and personal development.

I wish to thank Ron Stenkamp for allowing us to use his beautiful computer-averaged electron density maps, and to Larry Sieker for helping us to interpret the maps and for many productive discussions.

I would also like to thank Dr. Dennis Barnum for trusting me with his elegant and fragile titration apparatus; and to my friends, Bob Rempfer, Ann Corrigan, Rich Doty and Mali Paulis, who have helped me along every step of the way with their encouragement and scientific curiosity.

And to Larry, who somehow endured. 
TABLE OF CONTENTS

PAGE

ACKNOWLEDGEMENTS . . . . . . . . . . . . . . . . . . 1 . . . . .

LIST OF TABLES . . . . . . . . . . . . . . . . . . v v

LIST OF FIGURES . . . . . . . . . . . . . . . . . . . vi vi

INTRODUCTION . . . . . . . . . . . . . . . . . . 1

EXPERIMENTAL PROCEDURES . . . . . . . . . . . . . . . . 4

Hemerythrin from $\underline{\mathrm{P}}$ gouldii and $\underline{\mathrm{T}}$ dyscritum ...... 4

Spectrophotometric Titration . . . . . . . . . . 5

Column Chromatography . . . . . . . . . . . . 7

Materials . . . . . . . . . . . . . 8

RESULTS • . • . . . . . . . . . . . . . . . 9

Spectrophotometric Titrations . . . . . . . . . . 9

Hemerythrin Dissociation . . . . . . . . . . 15

DISCUSSION • . • • . . . . . . . . . . . . • • 23

Identification of the Mercuric Iodide Binding Site . . . 23

Identification of Subunit Interactions . . . . . . . 27

Chemical Modification of Cysteine Sulfurs . . . . . . 33 CONCLUSIONS • . . . . . . . . . . . . . . . . . 39

REFERENCES . . . . . . . . . . . . . . . . . . 41 


\section{LIST OF TABLES}

TABLE

PAGE

I Spectrophotometric Titration of Hemerythrin With Mercurials . . . . . . . . . . . . 13

II U1traviolet Absorption of Mercury Complexes . . . . . 15

III Hemerythrin Dissociation Products Resulting From Cysteine Modification .. . . . . . . . 16 


\section{LIST OF FIGURES}

FIGURE

PAGE

1. Quaternary Structure of Octameric Hemerythrin . . . . . 3

2. Temperature-controlled Titration Apparatus ... . . . . 6

3. Spectrophotometric Titration of $\underline{\mathrm{P}}$. gouldii Hemerythrin With PHMB .................. 10

4. Spectrophotometric Titration of Hemerythrin With PHMB . . . 11

5. Spectrophotometric Titration of Hemerythrin With $\mathrm{K}_{2} \mathrm{HgI}_{4} \cdot{ }^{-} 12$

6. Dissociation of Hemerythrin By NEM . . . . . . . . 17

7. Sephadex G-100 Chromatography of $\underline{T}$. dyscritum Hemerythrin

Reacted With Varying Amounts of PHMB . . . . . . . 18

8. Subunit Distribution of $\underline{T}$. dyscritum Hemerythrin Treated

With Varying Amounts of PHMB . . . . . . . . . 20

9. Sephadex G-100 Chromatography of T. dyscritum Hemerythrin

After Exposure to Sulfhydry1-specific Reagents . . . . 21

10. Proposed Mercury Binding Sites in $\underline{T}$. dyscritum Hemerythrin . 26

11. Diagram of Cis and Trans Subunit Interaction Sites . . . . 30

12. Identification of Residues Responsible for Trans Interaction . . . . . . . . . . . . . . . 31

13. Comparison of Amino Acid Sequences . . . . . . . . . . 32

14. Reaction Scheme for the Modification of Hemerythrins by

PHMB and NEM ................... 35 


\section{INTRODUCTION}

Hemerythrin is a respiratory protein found in the erythrocytes of certain marine invertebrates. The hemerythrin which has been studied in greatest detail is the one from the coelomic fluid of the Atlantic Coast sipunculid, Phascolopsis gouldi1 ( $\underline{P}$. gouldi1) $(1,2)$. The oxygen binding site structure has two iron atoms coordinated directly to amino acid residues. Each of the eight subunits comprising one hemerythrin molecule contains two iron atoms. Oxidation state alone does not play a role in maintenance of the octameric ensemble; however, the cysteine sulfhydryl group at residue 50 is crucially involved, as its modification can result in the stolchiometric conversion of octamers to monomers (3).

Although chemical and physical studies have revealed many details of hemerythrin structure (1-3), only recently have three dimensional models of hemerythrin been available which could serve to correlate previous studies. Structures have been obtained by $x$-ray crystallography for hemerythrin from $\underline{\text { P. gouldif }}(2,4)$ and from the Pacific Coast sipunculid, Themiste dyscritum (T. dyscritum) $(5,6)$. Upon solving the crystal structure of $\underline{T}$. dyscritum hemerythrin, two mercury binding sites were observed in the heavy atom derivative prepared by treating the protein with mercuric iodide. Since previous studies with $\underline{p}$. gouldii hemerythrin had indicated that binding of mercurials to the cysteine at position 50 caused dissociation of the protein (3), this raised the question of whether $\underline{T}$. dyscritum hemerythrin had a cysteine at position 
50 and, if so, whether cysteine residues were providing the binding sites for mercuric lodide.

A recent amino acid sequence analysis of $\underline{T}$. dyscritum hemerythrin revealed two cysteines: one at position 50 and an additional one at position 9 (7). Moreover, fitting of the amino acid sequence to the electron denisty map of $\underline{T}$. dyscritum hemerythrin showed that the mercuric lodide binding sites are close to the cysteine residues (Figure 1). One mercury is near the cysteine 50 residue of each subunit while the other mercury appears to be bridging cysteine 9 residues of adjacent subunits.

This study was undertaken to determine whether the mercury in the heavy atom derivative of $\underline{T}$. dyscritum hemerythrin was, in fact, covalently bound to cysteine sulfur atoms and, if so, to elucidate the structure of the mercury-sulfur complexes in the protein. It was also of interest to understand how mercuric lodide was able to bind to $\underline{T}$. dyscritum hemerythrin without causing it to dissociate into subunits, since many sulfhydryl-specific reagents are known to cause disruption of the octameric structure of $\underline{\mathrm{P}}$. gouldil hemerythrin (3).

The experimental approach to these questions involved a comparison of the relative reactivities of $\underline{p}$. gouldil and $\underline{T}$. dyscritum hemerythrins towards mercuric lodide and two other sulfhydryl group modifiers, phydroxymercuribenzoate (PHMB) and N-ethylmaleimide (NEM). The nature and extent of mercurial binding was studied by spectrophotometric titration. Gel filtration chromatography was used to quantitate the dissociation and to characterize the resulting products. Interpretation of experiments was aided by the availability of a computer-averaged electron density map for. T. dyscritum hemerythrin. 


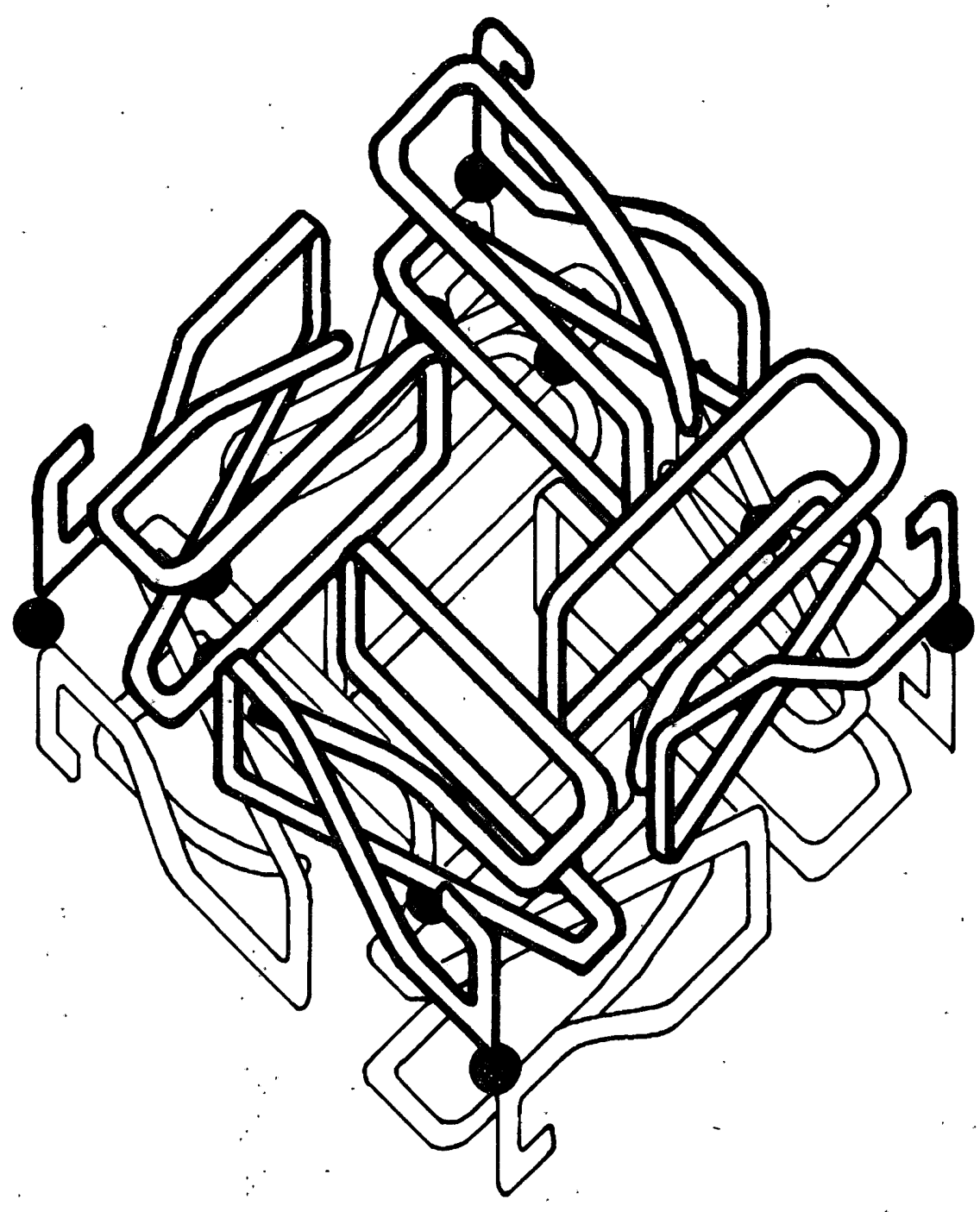

Figure 1. Quaternary structure of octameric hemerythrin. Drawing based on $\mathrm{x}$-ray crystallographic structure of $\mathrm{T}$. dyscritum hemerythrin at $5 \AA$ resolution (5). The elght subunits form a square antiprism which approximates $\mathrm{D}_{4}$ symmetry: a 4-fold axis perpendicular to the plane of the page and four 2-fold axes in the plane of the page. The $\mathrm{NH}_{2}$-terminal regions (near corners of square) are exposed to solvent. The molecule then loops back and forms four, roughly parallel stretches of $\propto-$ hellx (A,B,C and D helices) with the COOH-terminal. (D-helix) tucking down into the molecule. Black dots indicate locations of mercury atoms in the heavy atom derivative. A total of 12 mercury atoms are bound to the eight subunits. Each subunit has one mercury atom close to cysteine 50 (B helix) at the interface between the two layers and another mercury atom close to the cysteine 9 's of the two subunits in different layers (at the corners of the square). 
EXPERIMENTAL PROCEDURES

HEMERYTHRIN FROM $\underline{P}$. GOULDII AND $\underline{T}$. DYSCRITUM

The marine worms, $\underline{P} \cdot \underline{\text { gouldii }}$ and $\underline{T}$. dyscritum were obtained, respectively, from Marine Biological Laboratory, Woods Hole, Mass., and Oregon Institute of Marine Biology, Charleston, Oregon. Hemerythrin from both marine worms was purified by the following method adapted from Klotz et al. (8). Erythrocytes separated from the coelomic fluid by centrifugation ( 10 minutes at $1000 \mathrm{~g}$ ) were twice washed in $0.54 \mathrm{M}$ $\mathrm{NaCl}$ and lysed by addition of an equal volume of distilled water. The lysate was centrifuged (10 minutes at $27,000 \mathrm{~g}$ ) and the supernatant passed through a 0.45 micron Millipore filter with prefilter to remove any remaining cellular debris.

The conditions which favor hemerythrin crystallization, the final purification step, are dependent upon the species from which the protein is obtained. Crystallization of $\underline{P}$. gouldii hemerythrin was accomplished by dialysis against a large excess of $20 \%$ ethanol (8). Hemerythrin from $\underline{T}$. dyscritum was crystallized by dialysis against solutions of low ionic strength, the exact strength depending upon the age and concentration of the protein solution. Thus, fresh concentrated solutions crystallized when dialyzed versus $0.04 \mathrm{M} \mathrm{KCl}, 0.01 \mathrm{M} \mathrm{Tr}$ is $-\mathrm{Cl}$ ( $\mathrm{pH}$ 7.5), while older or more dilute preparations required slightly lower Ionic strength.

It was possible to convert hemerythrin to the metazido form by dialysis against $0.01 \mathrm{M}$ potassium ferricyanide, $0.5 \mathrm{M}$ sodium azide, $0.05 \mathrm{M}$ 
Tris-C1 ( $\mathrm{pH} 7.5)$, followed by repeated dialysis against the same solution without ferricyanide (9). However, a preferable procedure was to convert metchlorohemerythrin to the more stable metazido form before crystallization by the addition of a few milligrams of sodium azide to the crude 1ysate. This addition of sodium azide early in the preparation had the added advantage of inhibiting bacterial growth. The dialysis solutions used for the crystallization of $\underline{T}$. dyscritum and $\underline{P}$. gouldii hemerythrins were identical to those formerly described with the addition of sodium azide (0.01M). Crystals were harvested directly from the dialysis tubing by dissolving them in salt solution ( $1 \mathrm{M} \mathrm{KCl}$, 0.05M Tris-C1, $\mathrm{pH} \mathrm{7.5).}$

In the laked blood of $\underline{T}$. dyscritum, hemerythrin represents about $93 \%$ of the total protein present; after crystallization, more than $99 \%$ of all protein present is hemerythrin as judged by polyacrylamide gel electrophoresis in sodium dodecyl sulfate.

Protein subunit concentrations were determined spectrophotometrically using $\mathrm{E}_{327}=7200 \mathrm{M}^{-1} \mathrm{~cm}^{-1}$ for $\underline{\mathrm{P}}$. gouldii hemerythrin; and $\mathrm{E}_{325}=7750 \mathrm{M}^{-1}$ $\mathrm{cm}^{-1}$ for $\mathrm{T}$. dyscritum hemerythrin (10).

\section{SPECTROPHOTOMETRIC TITRATION}

Experiments were performed in $0.5 \mathrm{M} \mathrm{KCl}, 0.05 \mathrm{M} \operatorname{Tris}-\mathrm{Cl}(\mathrm{pH} 7)$ at $7 \pm 3^{\circ} \mathrm{C}$. Stock hemerythrin was prepared by crystallization of the metazido form and removal of the excess azide by dialysis, since azide absorbs strongly at the wavelength used to detect the mercury-sulfur bond formation. Just prior to use, aliquots were filtered, diluted, and the concentration determined. The protein subunit concentration ranged from 3 to $7 \times 10^{-5} \mathrm{M}$. in a reaction volume of $25 \mathrm{~m} 1$. Fresh mercurial 
titrant was prepared for each experiment at concentrations such that a maximum of $0.4 \mathrm{ml}$ of titrant was added per $25 \mathrm{ml}$ in the reaction vessel. Concentrated solutions of p-hydroxymercuribenzoate (PHMB) required addition of $\mathrm{KOH}$ to approximately $0.025 \mathrm{~N}$ to dissolve in the above buffer, while $\mathrm{HgI}_{2}$ was readily soluble in water containing a tenfold excess of $\mathrm{KI}$.

The titrations were performed at $250 \mathrm{~nm}$ on a Cary 14 spectrophotometer fitted with a temperature-controlled titration apparatus designed by Dr. Dennis Barnum (Figure 2). The cell holder consists of an aluminum block, bored to permit circulation from a Gilson multifunctional temperature controlled water bath (MSRO-2); ethylene glycol was added to

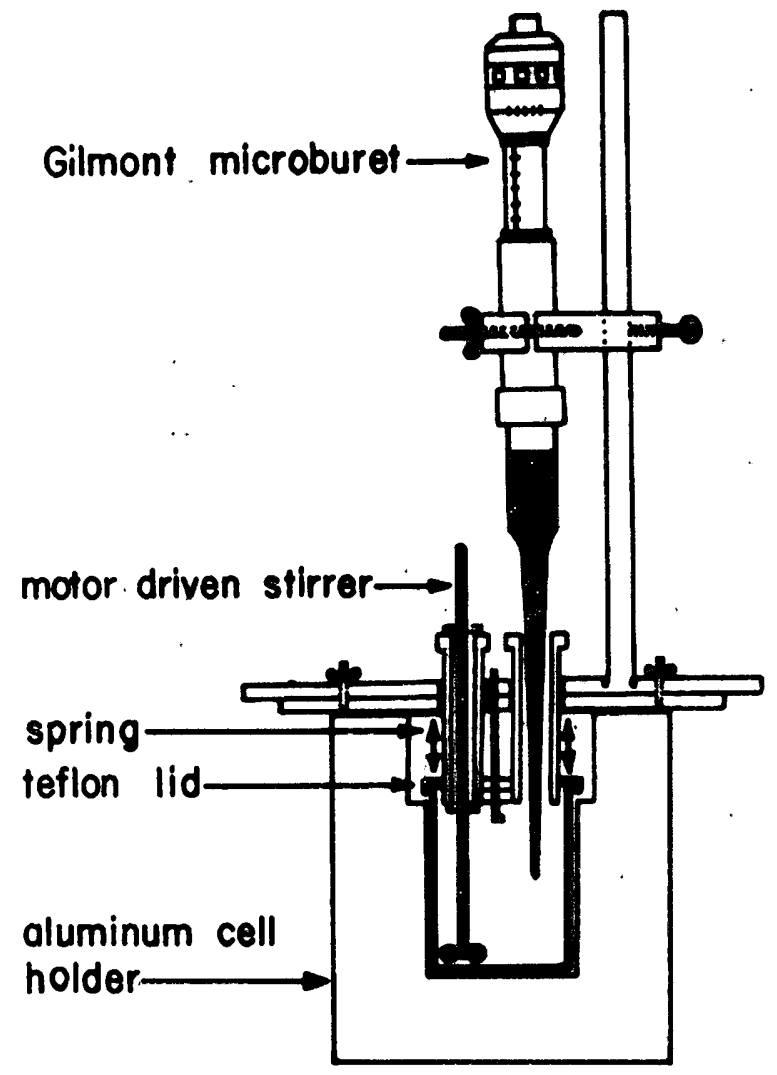

Figure 2. Temperature-controlled titration apparatus for the Cary 14 spectrophotometer. 
the circulating fluid for use in this temperature range. The block is fitted with two round quartz windows to allow passage of the light beam through a central rectangular chamber containing a $30 \mathrm{ml}(5.1 \mathrm{~cm} \mathrm{x}$ $2.2 \mathrm{~cm} \times 4.2 \mathrm{~cm})$ quartz cuvette. The mechanism has a connected doublelid system; an inner teflon lid is spring loaded to fit tightly over the cuvette, while an outer metal lid bolts to thè block. The teflon propeller-type stirrer and the glass tip of the Gilmont ultra-precision micrometer buret enter the chamber through two cylindrical teflon ports and emerge on either side of the light beam. Thus the sample solution is in contact with only teflon or glass. The sample chamber of the spectrophotometer was purged with nitrogen to prevent condensation of water vapor on optical surfaces. The $3 \mathrm{ml}$ ( $1 \mathrm{~cm}$ path 1 ength) reference cell was at room temperature and contained protein in the above buffer plus sufficient azide to cancel the initial absorbance of the protein in the sample cell. No drift was observed in the spectrophotometer baseline in 24 hours. In all experiments reported, no protein precipitation occurred either in the reference or the sample cell indicating negligible protein denaturation. Each experiment was performed at least twice.

\section{COLUMN CHROMATOGRAPHY}

Metazidohemerythrin from several preparations was used. As the crystallization procedure was altered during the time these experiments were performed, early reactions utilized hemerythrin crystallized in the metchloro form, while later experiments used the new crystallization procedure as described at the beginning of this section. All chromatography was performed at $4^{\circ} \mathrm{C}$ on a $1.5 \mathrm{~cm} \times 30 \mathrm{~cm}$ column packed with Sephadex G-100 (40-120 microns) and equilibrated in $0.5 \mathrm{M}$ sodium azide, $0.05 \mathrm{M}$ 
Tris-C1 (pH 8.0 to 8.5 ). Column eluant was collected in $0.5 \mathrm{ml}$ to $1 \mathrm{ml}$ fractions and assayed for protein content by its absorbance at $280 \mathrm{~nm}$ or 326nm on a Cary 14 spectrophotometer. The column was calibrated with proteins of known molecular weight in order to establish the relationship between elution volume and molecular weight. The proteins used for molecular weight calibration were ribonuclease (13,700 MW), myoglobin (17,200 MW), trypsin inhibitor (21,500 MW), ovalbumin (45,000 MW), bovine serum albumin $(66,000 \mathrm{MW})$, and conalbumin $(85,000 \mathrm{MW})$. The calibration was verified with $\underline{P}$. gouldii hemerythrin in the native, octameric form $(108,000 \mathrm{MW})$ and in the PHMB-dissociated monomeric form $(13,500 \mathrm{MW})$ which had been previously characterized by Kerestzes-Nagy and Klotz (3). Solutions were prepared as described in Spectrophotometric Titrations. Since N-ethylmaleimide (NEM) hydrolizes in azide and high $\mathrm{pH}$, it was dissolved and reacted with hemerythrin in $0.5 \mathrm{M} \mathrm{KC1}, 0.05 \mathrm{M} \operatorname{Tr}$ isC1 (pH 7.0). Aliquots of sulfhydryl reagent were added to solütions approximately $10^{-3} \mathrm{M}$ in hemerythrin and mixed on a vortex. This reaction mixture (not exceeding $0.5 \mathrm{ml}$ ) was incubated at $0^{\circ} \mathrm{C}$ prior to column application. Each reaction was performed at least twice with the exception of the mixed NEM-PHMB experiment.

\section{MATERIALS}

All reagents used were reagent grade. The Sephadex was purchased from Pharmacia, and the sodium azide was first recrystallized from acetone-water mixtures, then washed with acetone. 


\section{RESULTS}

\section{SPECTROPHOTOMETRIC TITRATIONS}

The number of reactive cysteines in a protein molecule can be determined by monitoring the increase in absorbance at $250 \mathrm{~nm}$ upon addition of a mercurial $(11,12)$. Titrations of hemerythrin suflhydryl groups were performed by adding a mercurial in discrete aliquots, each containing 0.25 moles of reagent per mole of subunit. The resulting increase in absorbance had two phases, as can be observed in Figure 3: an initial increase due to the absorbance of the added mercurial, followed by a less rapid increase due to absorbance by the newly-formed mercury sulfur bonds. Hemerythrin from $\underline{P}$. gouldi1 has only one reactive cysteine per subunit (3), and Figure 3 shows that no more $\mathrm{Hg}-\mathrm{S}$ bond formation is observed after 1 mole of PHMB has been added per mole of subunit.

Each reaction was allowed to go to completion, as evidenced by a levelling off of the absorbance. Figures 4 and 5 show the leve1-off absorbance values plotted as a function of the moles of titrant added. A change of slope occurs at the point where all sulfhydryl groups have been titrated: the point of intersection of the two lines thus formed gives values for both the moles of sulfhydryl groups titrated per subunit and the total absorbance of the sulfur mercury bonds formed. The results are summarized in Table $I$.

The titration of both hemerythrins with PHMB resulted in the reaction of only one PHMB per protein subunit as judged by the end-point of 


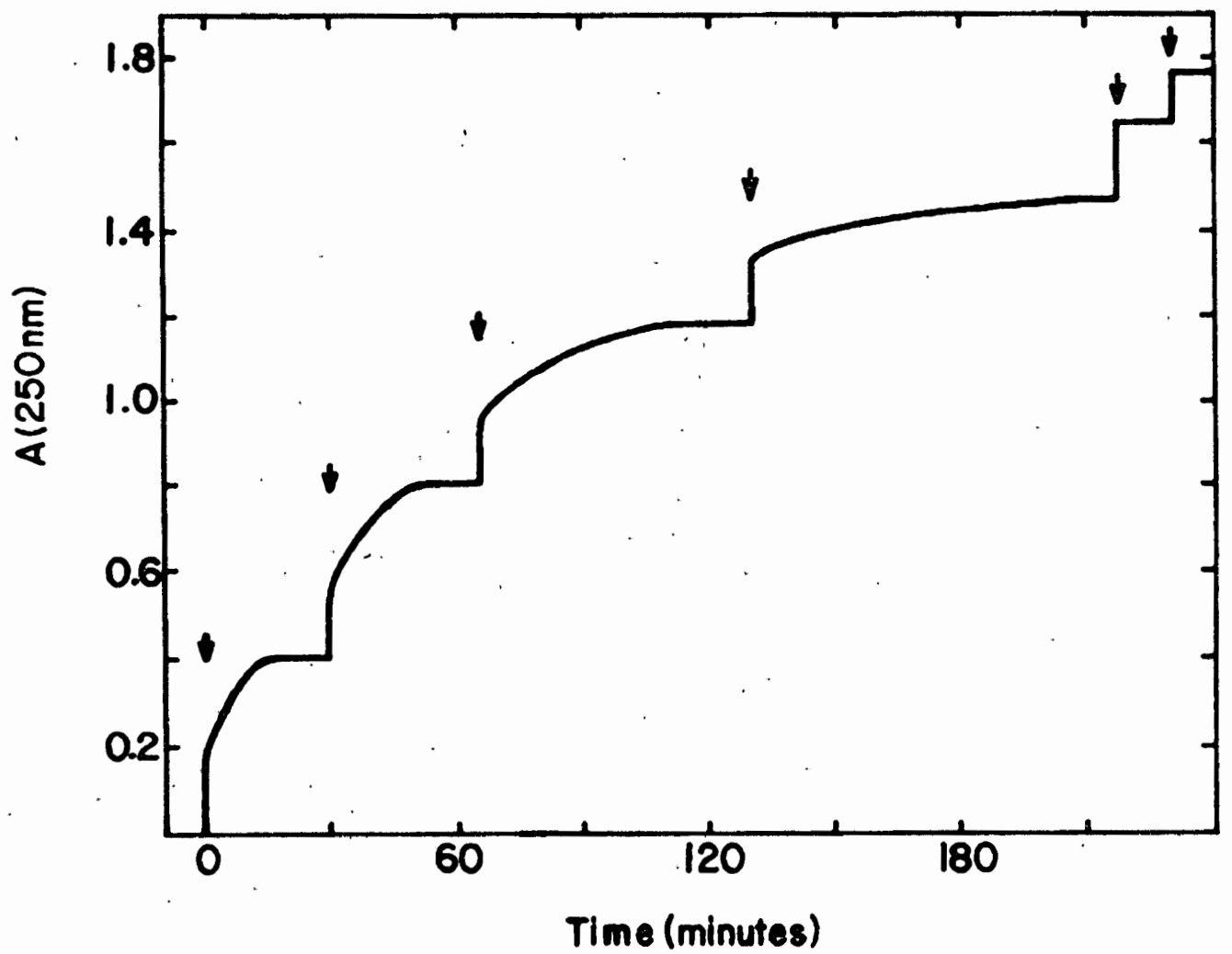

Figure 3. Spectrophotometric titration of $\underline{P}$. gouldii hemerythrin with PHMB. Arrows indicate the addition of 0.25 moles of PHMB per mole of subunit.

the titration and the close agreement of $\Delta \varepsilon_{250}$ values for $\mathrm{Hg}-\mathrm{S}$ bond formation (Figure 4, Table I). These values also agree with the published $\Delta \varepsilon_{250}$ values of $0.8 \times 10^{4} \mathrm{M}^{-1} \mathrm{~cm}^{-1}$ for $\mathrm{Hg}-\mathrm{S}$ bond formation plus $0.5 \times 10^{4} \mathrm{M}^{-1} \mathrm{~cm}^{-1}$ for mercuribenzoate (12). Thus, only one of the two cysteine residues in $\underline{T}$. dyscritum hemerythrin reacts readily with PHMB $\left(t_{\frac{1}{2}}<1 \mathrm{hr}\right)$. By analogy to $\underline{\mathrm{P}}$. gouldii hemerythrin, it is 1ikely that cysteine 50 in $\mathrm{T}$. dyscritum hemerythrin is more reactive towards PHMB than is cysteine 9. A further slow reaction of $\underline{T}$. dyscritum hemerythrin with PHMB $\left(t_{\frac{1}{2}} \simeq 10 \mathrm{hrs}\right)$, presumably involving cysteine 9, was observed in titrations in whibh the hemerythrin was incubated for 4-8 hours with excess PHMB. However, in the results reported in Figure 

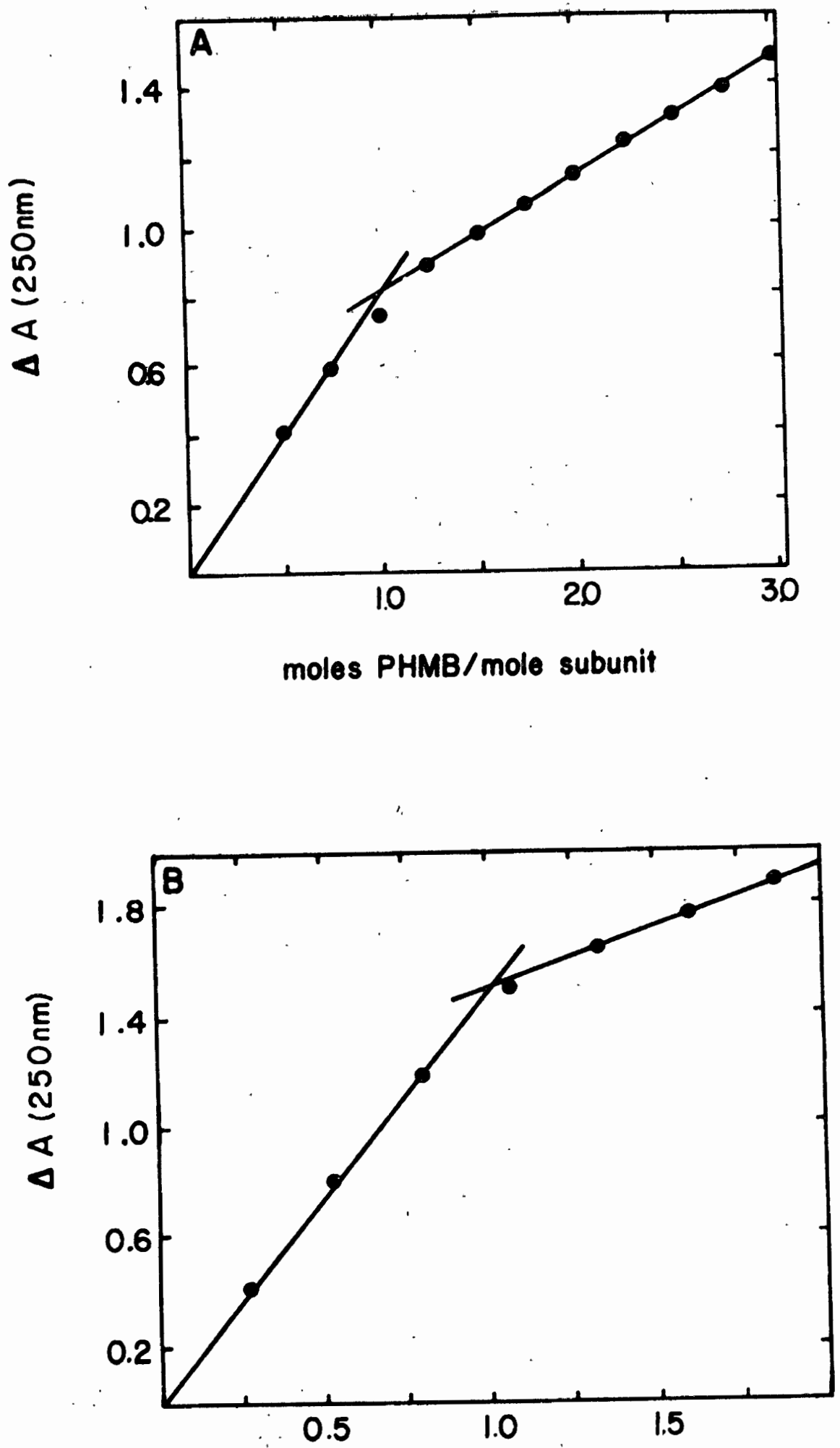

moles PHMB/mole subunit

Figure 4. Spectrophotometric titration of Hemerythrin with PHMB. A. Hemerythrin $\left(3.2 \times 10^{-5} \mathrm{M}\right)$. from T. dyscritum. B. Hemerythrin $\left(6.1 \times 10^{-5} \mathrm{M}\right)$ from $\underline{\mathrm{P}}$. gouldif. 

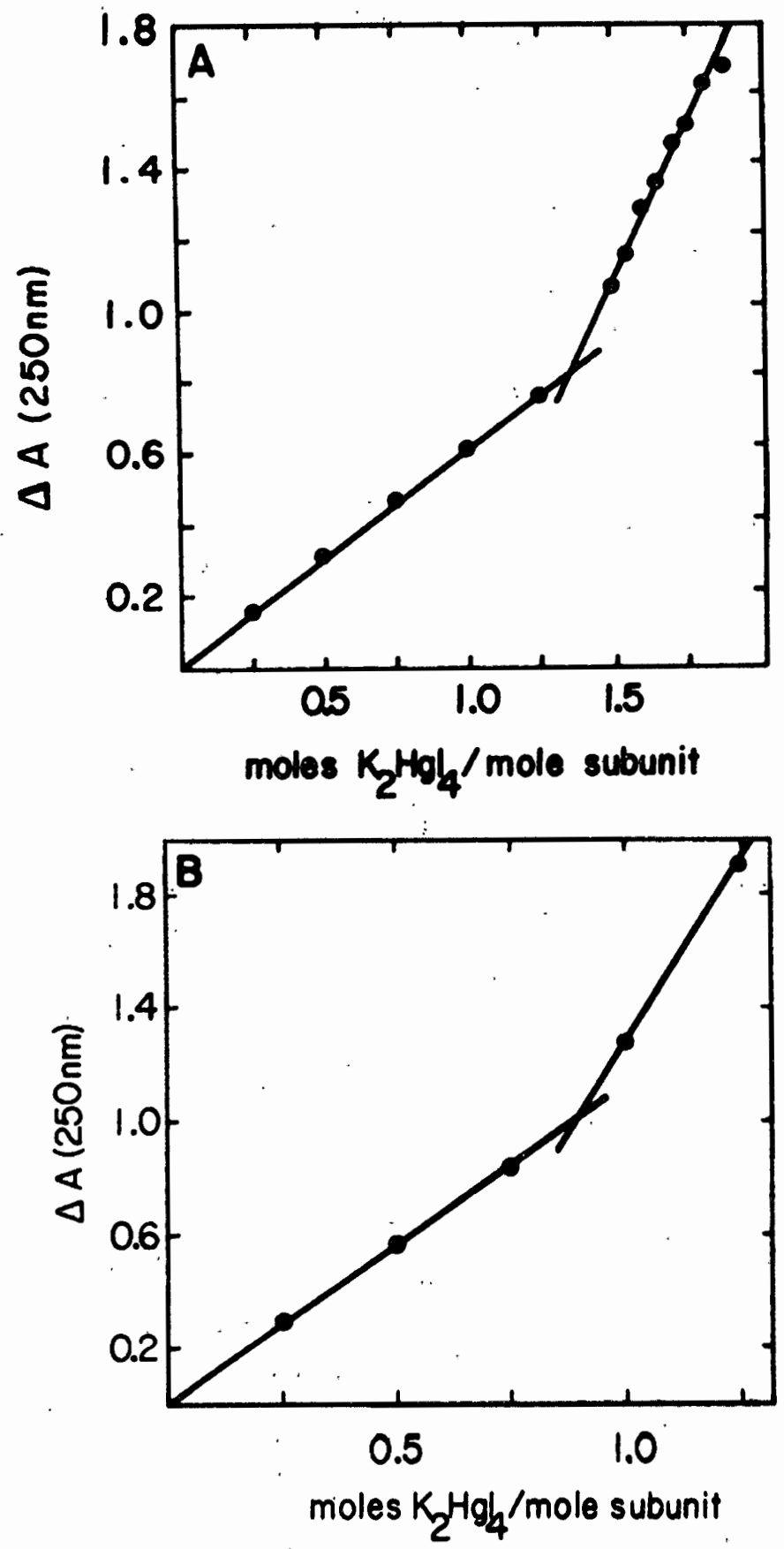

Figure 5. Spectrophotometric titration of hemerythrin with $\mathrm{K}_{2} \mathrm{HgI}_{4}$. A. Hemerythrin $\left(3.6 \times 10^{-5} \mathrm{M}\right)$ from $\mathrm{T}$. dyscritum. B. Hemerythrin $\left(6.4 \times 10^{-5} \mathrm{M}\right)$ from $\underline{\mathrm{P}}$. gouldi1. 
4, the incubations with excess PHMB were of much shorter duration (approximately 1 hour each) so that the reaction at the second cysteine was negligible.

TABLE I

SPECTROPHOTOMETRIC TITRATION OF HEMERYTHRIN WITH MERCURIALS

\begin{tabular}{|c|c|c|c|c|}
\hline Species & Reagent & $\frac{\text { Mole mercury }}{\text { Mole subunit }}$ & $\Delta \varepsilon_{250 \mathrm{~nm}}{ }^{a, b}$ & $\Delta \varepsilon_{284} \mathrm{~nm}^{c}$ \\
\hline P. gouldi1 & PHMB & 1.0 & $1.24 \times 10^{4}$ & . \\
\hline T. dyscritum & PHMB & 1.0 & $1.30 \times 10^{4}$ & \\
\hline P. gouldi1 & $\mathrm{K}_{2} \mathrm{HgI}_{4}$ & 0.9 & $0.87 \times 10^{4}$ & $0.12 \times 10^{4}$ \\
\hline T. dyscritum & $\mathrm{K}_{2} \mathrm{HgI}_{4}$ & 1.4 & $0.82 \times 10^{4}$ & $0.24 \times 10^{4}$ \\
\hline
\end{tabular}

a. Values from the end-point of the titration curves (Figures 4 and 5).

b. Absorptivity in $\mathrm{M}^{-1} \mathrm{~cm}^{-1}$ calculated by dividing the $\Delta \mathrm{A}_{250}$ by the mercury concentration and the $2 \mathrm{~cm}$ path length.

c. Absorptivity in $\mathrm{M}^{-1} \mathrm{~cm}^{-1}$ calculated by dividing the $\Delta \mathrm{A}_{284}$ value by the mercury concentration for hemerythrin reacted with 0.9 ( . gouldii) and 1.4 ( $\mathrm{T}$. dyscritum) moles mercury per mole subunit in $1 \mathrm{~cm} \mathrm{cells.}$

A more striking difference between the hemerythrins from the two species appeared when $\mathrm{K}_{2} \mathrm{HgI}_{4}$ was used as the titrating agent. In this case hemerythrin from $T$. dyscritum appeared to bind more than the one mercury per subunit observed for $\underline{P}$. gouldil hemerythrin (Figure 5, Table I). The endpoint of the titration curve for $\underline{T}$. dyscritum hemerythrin is consistent with 1.5 moles $\mathrm{Hg}$ bound per subunit expected if one of the two cysteines is being crosslinked to a cysteine from another subunit. This finding agrees well with the $x$-ray crystallographic data for $\underline{T}$. dyscritum hemerythrin reacted with $\mathrm{K}_{2} \mathrm{HgI}_{4}$, which indicates one 
Hg binding site at a position close to cysteine 9 (5).

Although the $\Delta \varepsilon$ at $250 \mathrm{~nm}$ for $\underline{T}$. dyscritum hemerythrin treated with mercuric iodide is similar to the value for $\underline{P}$. gouldii hemerythrin, the T. dyscritum protein shows considerably. greater $\Delta \varepsilon$ values in the 260 to $350 \mathrm{~nm}$ region, with the maximal absorption increase at $284 \mathrm{~nm}$ (Table I). The actual absorptivity of the mercury coordinated to cysteine 9 in $\underline{T}$. dyscritum hemerythrin can be calculated from the following relationship:

$$
\Delta \varepsilon_{284(50+9)}=\frac{\left[\mathrm{Hg}_{(9)}\right]}{\left[\mathrm{Hg}_{(50+9)}\right]} \Delta \varepsilon_{284(9)}+\frac{\left[\mathrm{Hg}_{50}\right]}{\left[\mathrm{Hg}_{(50+9)}\right]} \cdot \Delta \varepsilon_{284(50)}
$$

where: $\quad\left[\mathrm{Hg}_{(50+9)}\right] \equiv \begin{aligned} & \mathrm{Hg} \text { bound to cysteine } 9+50 \text { (model is } \mathrm{T} \text {. dyscritum } \\ & \text { hemerythrin). }\end{aligned}$ $\left.{ }^{[\mathrm{Hg}}(50)\right] \equiv \begin{aligned} & \mathrm{Hg} \text { bound to cysteine } 50 \text { (model is } \underline{\mathrm{P}} \text {. gouldii } \\ & \text { hemerythrin). }\end{aligned}$ $\left[\mathrm{Hg}_{(9)} \mathrm{I} \equiv \mathrm{Hg}\right.$ bound to cysteine 9. (the difference between
$\mathrm{Hg}_{(50+9)}$ and $\left.\mathrm{Hg}_{(50)}\right)$. $\Delta \varepsilon_{284(50+9)} \equiv$ Absorbtivity of Hg-cysteine $50+\mathrm{Hg}$-cysteine 9 complex (model is $\mathrm{T}$. dyscritum hemerythrin). $\begin{aligned} \Delta \varepsilon_{284(50) \equiv} \equiv & \text { Absorbtivity of Hg-cysteine } 50 \text { complex (model } \\ & \text { is } \underline{P} \text {. gouldii hemerythrin). }\end{aligned}$

$\Delta \varepsilon_{284(9)} \quad \equiv$ Absorbtivity of Hg-cysteine 9 complex.

Substituting in values from Table I:

$$
0.24 \times 10^{4}=\frac{0.5}{1.4} \quad \Delta \varepsilon_{284(9)}+\frac{0.9}{1.4} \quad 0.12 \times 10^{4}
$$

Therefore, the $\Delta \varepsilon_{284}$ per $\mathrm{Hg}$ at cysteine 9 is $0.46 \times 10^{4} \mathrm{M}^{-1} \mathrm{~cm}^{-1}$. Comparison of the $\mathrm{Hg}$ at Cys 9 value with the uv absorption of simple mercury complexes (Table II) indicates that the location and intensity of the absorption maximum at $284 \mathrm{~nm}$ are consistent with the mercury at 
cysteine 9 being coordinated to two halides in addition to two sulfur atoms.

TABLE II

ULTRAVIOLET ABSORPTION OF MERCURY COMPLEXES

\begin{tabular}{|l|c|c|}
\hline \multicolumn{2}{|c|}{ Complex $^{\text {a }}$} & \multicolumn{2}{|c|}{$\varepsilon_{\lambda \max }$ in $\mathrm{M}^{-1} \mathrm{~cm}^{-1}$} \\
\hline $\mathrm{HgI}_{2}$ & 273 & $0.57 \times 10^{4}$ \\
$\mathrm{~K}_{2} \mathrm{HgI}_{4}$ & 282 & $0.83 \times 10^{4}$ \\
$\mathrm{Hg}(\text { Cys })_{2}$ & 298 & $0.55 \times 10^{4}$ \\
$\mathrm{Hg}\left(\right.$ Cys ${ }_{2}$ & $(280)^{\mathrm{b}}$ & $0.09 \times 10^{4}$ \\
\hline
\end{tabular}

a. $\mathrm{HgI}_{2}$ in ethanol; $\mathrm{K}_{2} \mathrm{HgI}_{4}$ in water with 10 -fold excess of $\mathrm{KI}$; $\mathrm{Hg}$ (Cys) $\mathrm{Cl}_{2}$ prepared as described in reference $11 \mathrm{la}$ in $1: 1$ ethanol: water, $0.01 \mathrm{M}$ in $\mathrm{HCl}$; $\mathrm{Hg}$ (Cys) 2 prepared as described in reference 11a but dissolved in water without ethanol.

b. This complex has no observable absorption maxima above $240 \mathrm{~nm}$.

\section{HEMERYTHRIN DISSOCIATION}

The dissociation behavior of $\underline{P}$. gouldil hemerythrin has been extensively studied by Keresztes-Nagy and Klotz, who found that treatment of the native octameric protein with certain sulfhydryl group modifying reagents was sufficient to cause dissociation into monomers $(3,14)$. For our study three sulfhydryl-specific reagents were chosen: the organic mercurial, $\mathrm{PHMB}$, the inorganic mercurial, $\mathrm{K}_{2} \mathrm{HgI}_{4}$, and the organic reagent, NEM. Since the $\mathrm{K}_{2} \mathrm{HgI}_{4}$ solution probably contains a mixture of $\mathrm{HgI}_{4}{ }^{\mp}, \mathrm{HgI}_{3}{ }^{-}$and $\mathrm{HgI}_{2}$, it will be referred to henceforth as mercuric iodide. Identification of dissociation products was accomplished by gelfiltration, relating elution volumes to molecular weights. For the 
sephadex G-100 column used, the Ve/Vo values for the octamer $(108,000$. MW), dimer $(27,000 \mathrm{MW})$ and monomer $(13,000 \mathrm{MW})$ were found to be, respectively: $1.3,1.7$, and 2.0 .

Table III outlines the results observed after reacting hemerythrin from each species with sulfhydry1-specific reagents. The results obtained with $\underline{P}$. gouldil hemerythrin are consistant with those previously reported (3) in that the protein is completely dissociated by PHMB and NEM, but not by mercuric lodide. Hemerythrin from $T$. dyscritum is simi-

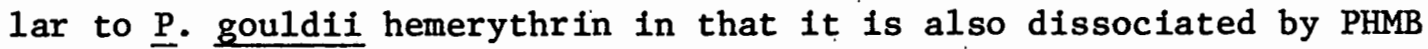
and NEM and not by mercuric iodide. However, the hemerythrins from the two species differ in their dissociation by PHMB and NEM in the types of products formed and in the rates of reaction.

TABLE III

HEMERYTHRIN DISSOCIATION PRODUCTS RESULTING FROM CYSTEINE MODIFICATION

\begin{tabular}{|c|c|c|c|c|c|c|}
\hline species & reagent & $\frac{\text { moles reagent }}{\text { mole protein }}$ & $\begin{array}{l}\text { reaction } \\
\text { time (hrs) }\end{array}$ & $\frac{\text { dissocia }}{\text { octamer }}$ & $\frac{\text { tion } p}{\text { dimer }}$ & $\frac{\text { roducts }(\%)}{\text { monomer }}$ \\
\hline P. gouldii & $\begin{array}{l}\text { PHMB } \\
\text { NEM } \\
\mathrm{K}_{2} \mathrm{HgI}_{4}\end{array}$ & $\begin{array}{r}2.0 \\
10.0 \\
1.0\end{array}$ & $\begin{array}{r}4 \\
53 \\
24\end{array}$ & 80 & & $\begin{array}{r}100 \\
100 \\
20\end{array}$ \\
\hline F. dyscritum & $\begin{array}{l}\text { PHMB } \\
\text { NEM } \\
\mathrm{K}_{2} \mathrm{HgI}_{4}\end{array}$ & $\begin{array}{r}2.0 \\
10.0 \\
1.5\end{array}$ & $\begin{array}{r}6 \\
52 \\
20\end{array}$ & $\begin{array}{r}60 \\
100\end{array}$ & $\begin{array}{l}70 \\
40\end{array}$ & 30 \\
\hline
\end{tabular}


As can be seen in Table III, reaction of $\underline{P}$. gouldii hemerythrin with PHMB produces monomers while reaction of $\underline{T}$. dyscritum hemerythrin with PHMB produces primarily dimers. In both cases, the majority of the dissociation occurred within the first hour after PHMB addition. NEM also dissociates $\underline{T}$. dyscritum hemerythrin into dimers. However, NEM reacts much more slowly with $\underline{T}$. dyscritum hemerythrin and does not appear to go to completion even with long reaction times (Figure 6 , Table III).

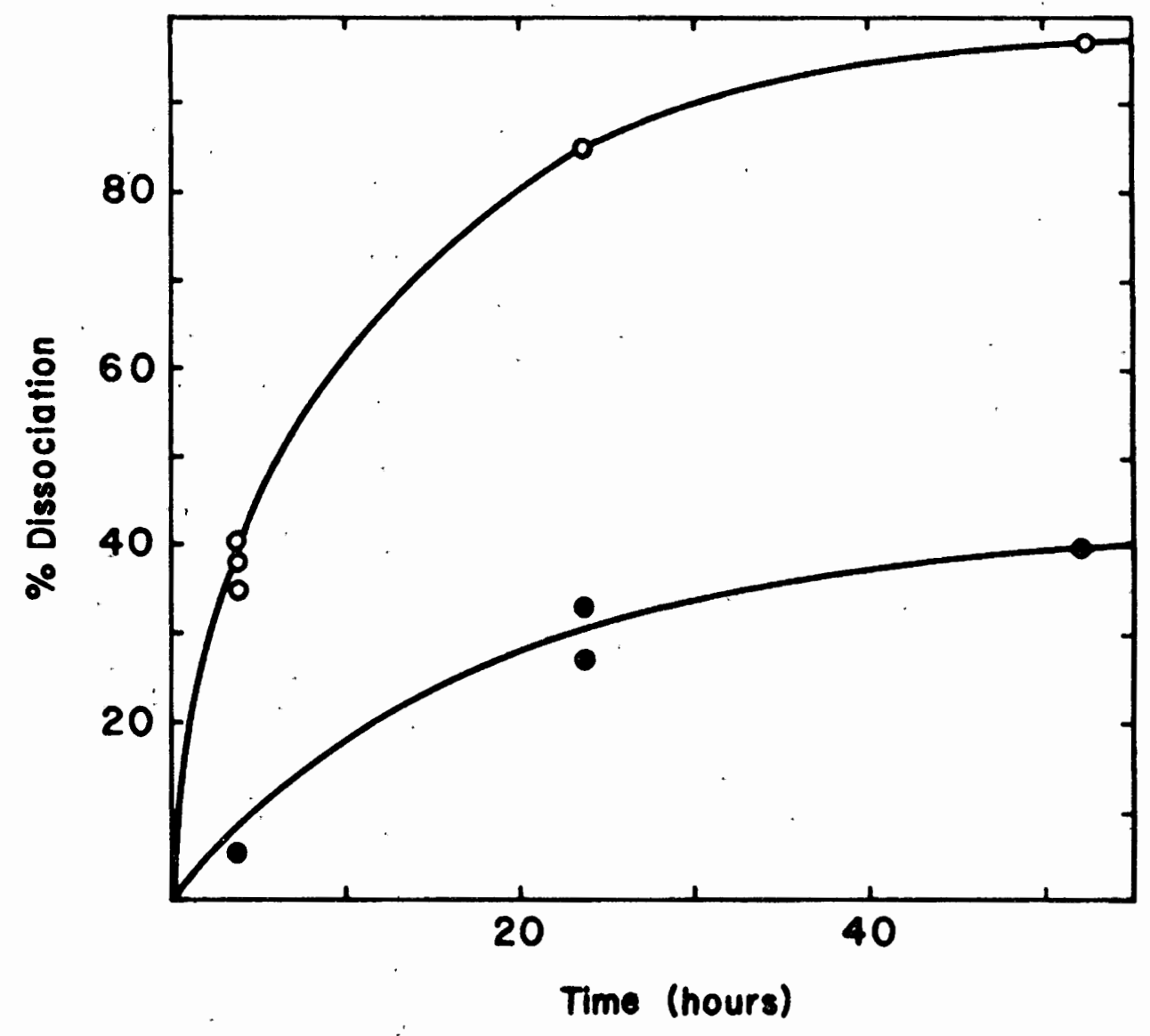

Figure 6. Dissociation of hemerythrin by NEM. Hemerythrin from $\underline{\text {. gouldii }}(0)$ and from . dyscritum $(\bullet)$. 


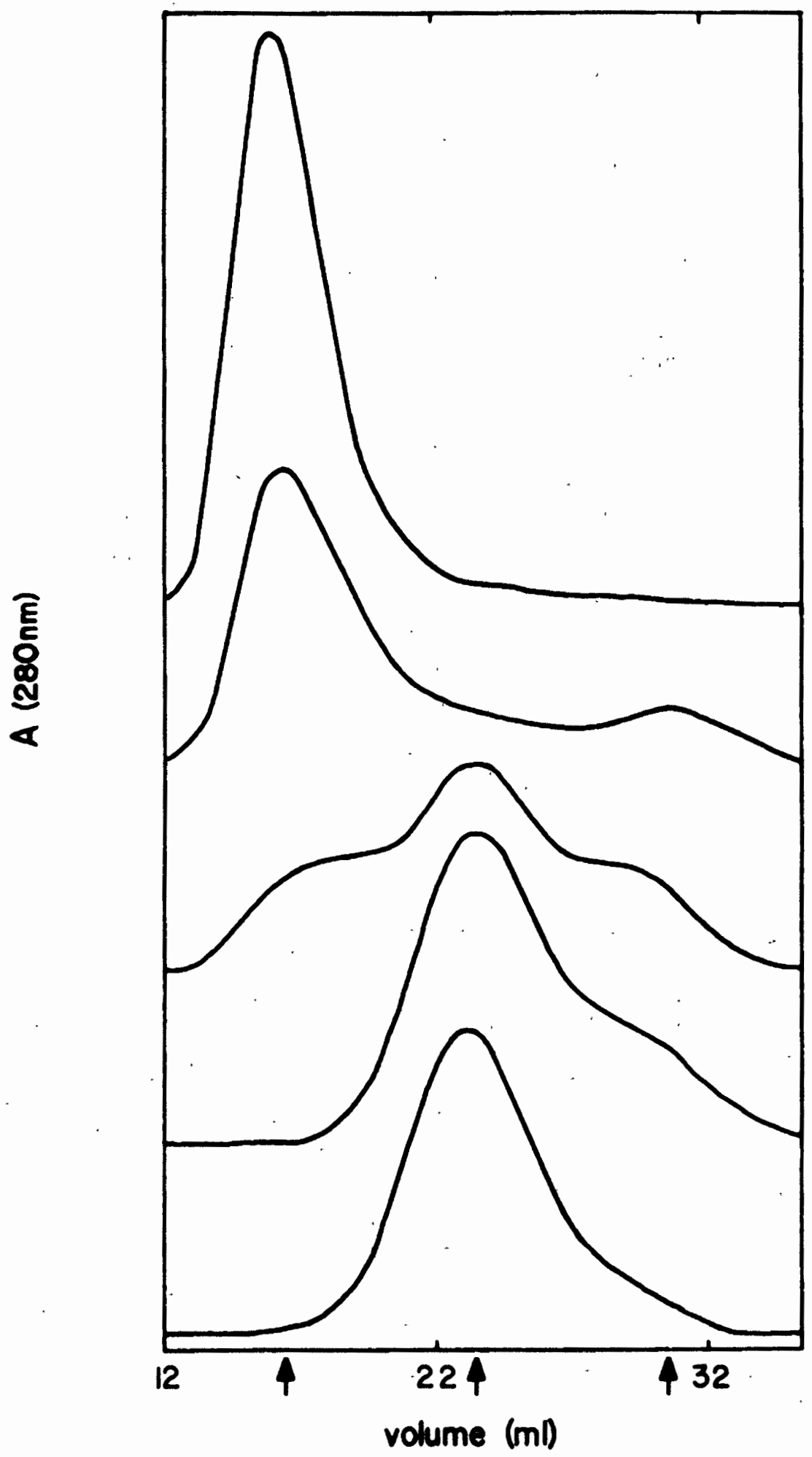

Figure 7. Sephadex (G-100 chromatography of T. dyscritum hemerythrin reacted with varying amounts of PHMB. Moles PHMB per mole of subunit from upper curve to lower: $0,0.5,1.0,1.25$, and 1.5 . Reactions times at $4^{\circ}$ varied from 20 hours for the smallest PHMB addition to 76 hours for the largest PHMB addition. Arrows indicate elution volumes of octamers (left), dimers (middle) and monomers (right). 
In an effort to study $\underline{T}$. dyscritum hemerythrin's dimerization phenomenon more closely, an experiment parallel in design to the spectrophotometric titration was performed. The two sulfhydry1 groups were titrated stepwise. with PHMB and the dissociation products for each step evaluated by column chromatography. As can be seen in Figures 7 and 8 , at $\mathrm{PHMB} /$ subunit ratios below 0.5 the primary dissociation product is a monomer. As the $\mathrm{PHMB} /$ subunit ratio increases above 0.5 , dimers become the major dissociation product. Thus, it appears that reaction of $\underline{T}$. dyscritum hemerythrin with PHMB involves an initial dissociation into monomers which is followed by dimerization. It is likely that the dissociation is caused by the rapid modification of cysteine 50 and the dimerization is caused by the slower reaction at cysteine 9 . Figure 8 also shows that only 1.5 moles of PHMB per subunit are necessary for dimerization (e.g. at 1 mole PHMB per mole subunit if 0.75 moles PHMB have reacted at cysteine 50 to produce $75 \%$ dissociation, then the 0.25 moles which reacted at cysteine 9 were sufficient to produce 0.5 moles of dimer).

To get a clearer picture of the reactions occurring at each sulfhydryl group, an additional experiment was performed in which the protein was reacted for a short period of time with NEM followed by a brief reaction with $\mathrm{PHMB}$. Dissociation products were analyzed after each reaction by column chromatography. Figure 9-A. shows that in the short incubation with NEM, no dissociation had occurred. The following two hour incubation with PHMB produced only dimers (Figure 9-B). However, a two-hour reaction of $\underline{T}$. dyscritum hemerythrin with PHMB alone would have produced mainly monomers due to the more rapid reaction of PHMB with cysteine 50 than cysteine 9. The fact that a reaction with 


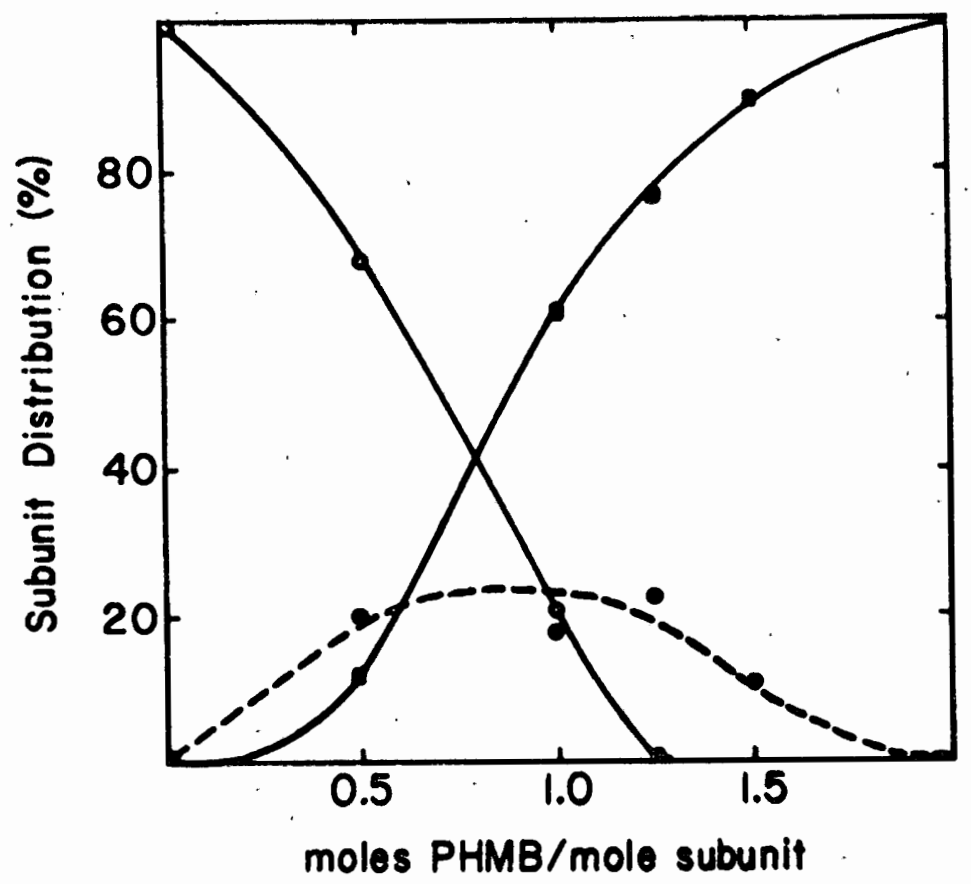

Figure 8. Subunit distribution of T. dyscritum hemerythrin treated with varying amounts of PHMB. Based on quantities of octamer, 0 ; dimer, $\square$; and monomer, $\bullet$; observed in Figure 7. 


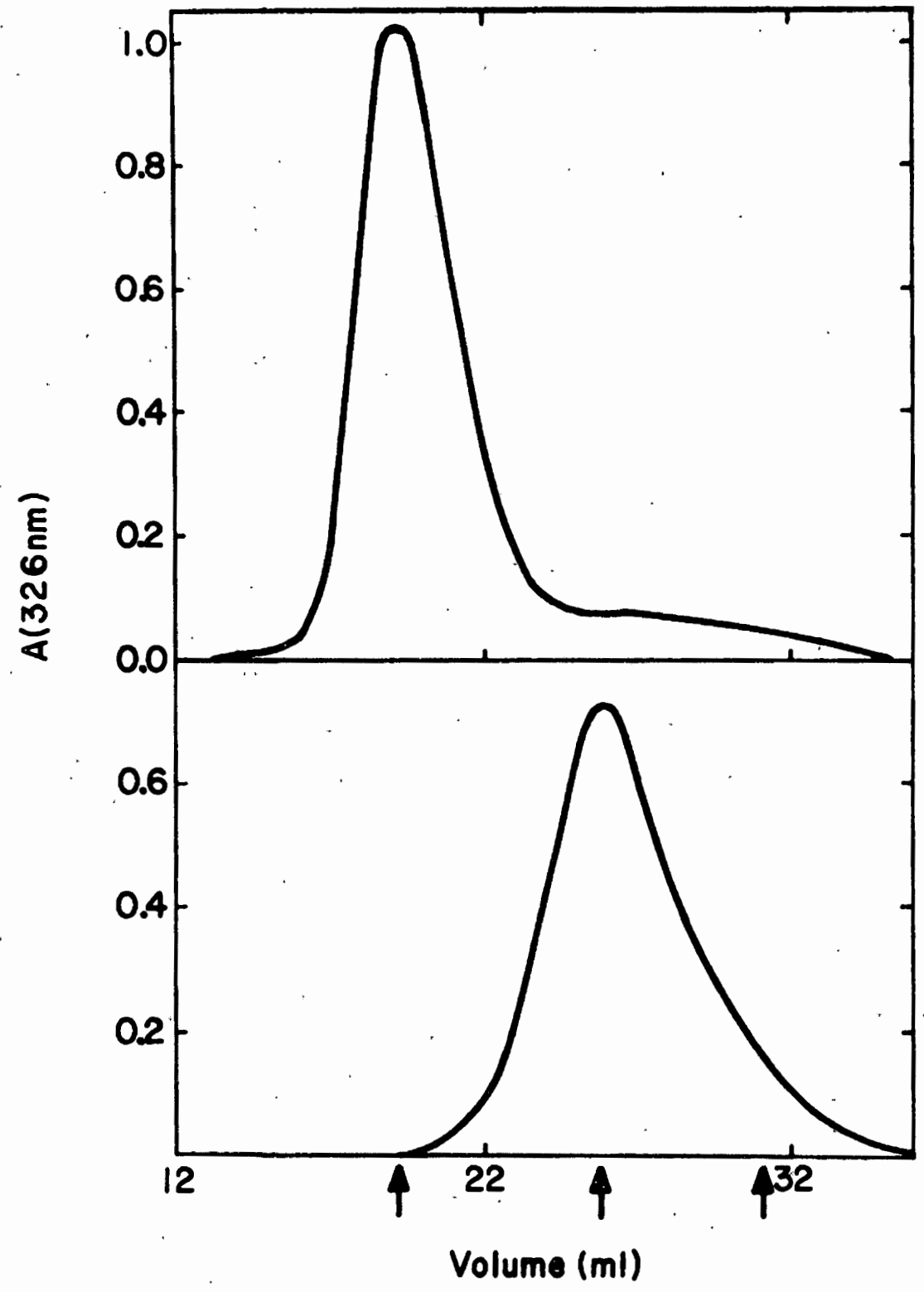

Figure 9. Sephadex G-100 chromatography of T. dyscritum hemerythrin after exposure to NEM and PHMB. Upper: Protein incubated $3.5 \mathrm{hr}$ with 10 moles NEM per mole subunit. Lower: Protein reacted with NEM as in $A$, dialyzed to remove unreacted NEM, and then incubated 2 hr with 2 moles PHMB per mole subunit. Arrows indicate elution volumes of octamers (left), dimers (middle) and monomers (right). 
NEM prior to PHMB greatly increases dimer production indicates that NEM reacts rapidly with cysteine 9 , while PHMB reacts rapidly with cysteine 50. 


\section{DISCUSSION}

\section{IDENTIFICATION OF THE MERCURIC IODIDE BINDING SITES}

Public attention has recently been focused on mercury poisoning because of the widely publicized disaster at Minimata Bay, Japan. Heavy metals such as mercury tend to be transported in organisms by blood plasma proteins. Mercury is sequestered in many tissues, but especially in the kidney where it is bound to the soluble protein, metallothionein.

In order to understand the nature of heavy-metal protein interactions it is necessary to identify metalloprotein ligands. However, the task of ligand identification is very difficult since most metal ions are bound through several protein ligands in a specific threedimensional arrangement, the interaction depending critically on the correct protein conformation. Identification of ligands by chemical analysis is often complicated by concomitant denaturation or degradation of the protein. An important source of data on intact protein is from $x$-ray analysis, where protein crystallographers have long taken advantage of heavy-metal lons to label proteins for use in the method of isomorphous replacement (15). However, x-ray diffraction maps show the heavy metal's position in the protein more precisely than that of the protein 1igands and it is often difficult to fix the precise orientation of the liganding side chains or the geometry of the metal, as protein maps are not usually at atomic resolution. The task of metal ligand 1dentification is facilitated by combining data from both sources, $\mathrm{x}$-ray analysis and chemical studies. 
depends upon the identity and surrounding environment of the 1igands. In the continuum of possible mercuric Ion 1igands, from those preferring digonal to those preferring tetrahedral, sulfur and iodide occupy a transitional position (18). Thus, mercuric complexes with mixed lodide and sulfur ligands could be either tetrahedral or digonal.

Since the actual reactive species of mercuric halide depends on the environment, the microenvironment around the protein thiol group is the deciding factor in determining the coordination of the thiolmercuric iodide complex. Dissociation of $\mathrm{HgI}_{4}{ }^{2-}$ to $\mathrm{HgI}_{2}+2 \mathrm{I}^{-}$is favored as the polarity of the medium decreases (17). Therefore, the neutral $\mathrm{HgI}_{2}$ would be the reactive species in a hydrophobic environment, whereas $\mathrm{HgI}_{4}{ }^{2-}$ would be the reactive species in a hydrophilic environment.

Mercuric iodide complexes react covalently with thiols by displacement of iodide ions (15). The $\mathrm{HgI}_{2}$ species is likely to be the one which reacts. with cysteine 50 in hemerythrin, since the crystallography has shown that cysteine 50 is buried in an interface between two subunits and our work has shown that it is more accessible to hydrophobic sulfhydryl reagents than hydrophilic ones. The reaction of cysteine 50 with $\mathrm{HgI}_{2}$ would result in a linear structure, as proposed in Figure 10. This agrees with the crystallographic study which interprets the heavy atom binding site near residue 50 as a prolate ellipsoid (5).

The $\mathrm{HgI}_{4}{ }^{2-}$ species is likely to be the one which reacts at cysteine 9, as the electron density maps show this region as a polar area of the molecule. The mercury observed by crystallography appeared to be bridging two cysteine $9^{\prime}$ 's from adjacent subunits across the twofold axis through the corners of the molecule. The shape generated by the 
mercury was described as an oblate elipsoid (5). The geometry best fitting this shape is a four coordinate, tetrahedral mercury complex (Figure 10): The tetrahedral assignment for mercury bound to cysteine 9 is supported by the presence of an absorption maximum at $284 \mathrm{~nm}$ (Table 1) indicative of two additional halogen ions coordinated to the mercury.

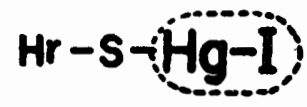

cysteine 50

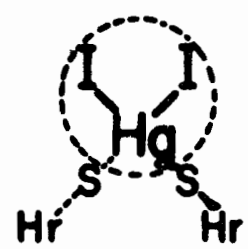

cysteine 9

Figure 10. 'Proposed mercury binding sites in T. dyscritum hemerythrin (Hr). Dotted lines show atoms responsible for observed ellipsoids; prolate at cysteine 50 and oblate at cysteine 9.

Complexes in which two sulfurs are bridged by mercury have recently been obtained by reacting $\mathrm{HgCl}_{2}$ with cysteine (13). Although the linear $\mathrm{Hg}$ (cysteine) 2 complex is more stable, a tetrahedral $\mathrm{Hg}$ (cysteine) $\mathrm{Cl}_{2} \mathrm{com}^{\mathrm{c}}$ plex was also crystallized and characterized. Our interpretation is that the mercury which bridges the cysteine 9 sulfurs in $\underline{T}$. dyscritum hemerythrin is more likely to be tetrahedral than linear because iodides form tetrahedral mercury complexes more readily than chlorides (18).

Since the cysteine 9 residues on adjacent subunits are close enough to be cross-1inked by mercury, one might expect them to have formed a disulfide bond in the native protein. However, there is no evidence for the existence of a disulfide bond. Cysteine 9 reacts readily with mercuric iodide and other sulfhydryl reagents, whereas cysteines involved in disulfide bonds must be reduced before they will react with 
sulfhydryl reagents (19). Observation of the location of the cysteine 9 residues in electron density maps indicate that the sulfur atoms are approximately $4 \AA$ apart and are prevented from closer approach by neighboring tyrosines at position 8 whose phenolate groups are buried inside the protein. The distance between the sulfur atoms in the tetrahedral (cysteine) ${ }_{2} \mathrm{HgCl}_{2}$ complex is $4.6 \AA$ (13) and would presumably be similar in a tetrahedral lodide complex.

\section{IDENTIFICATION OF SUBUNIT INTERACTIONS}

Many globular proteins, such as hemerythrin, occur as specific aggregates of noncovalently bound subunits. Two of the major reasons soluble proteins aggregate are: to promote allosteric interactions and to reduce the cellular osmotic pressure. Since hemerythrin comprises over $90 \%$ of the soluble protein contained in sipunculid blood cells and since hemerythrin subunits do not show cooperativity upon oxygen binding (20), the purpose of aggregation is probably to reduce the effective protein concentration.

Noncovalent bonding is widely used by biological macromolecules to maintain secondary, tertiary, and quaternary structure. Since noncovalent interactions (e.g. hydrophobic, electrostatic, and hydrogen bonding) are important in three different levels of protein structure, the task of identifying the specific amino acid interactions responsible for the stabilization of any one level is difficult. However, the identification of amino acids specifically responsible for subunit binding is possible because these amino acids are often susceptible to chemical modification and the resulting subunits generally retain biological activity. Moreover, when structural data is available from 
x-ray analysis and combined with information from chemical modification studies, the amino acid residues responsible for quaternary structure can be identified with some certainty. For our interpretation of subunit interactions in octameric hemerythrin, we have used a $2.8 \AA$ resolution, computer-averaged electron density map for $\underline{T}$. dyscritum hemerythrin provided by Ron Stenkamp. Many of our observations are also applied to $\underline{P}$. gouldii hemerythrin which is similar to $\underline{T}$. dyscritum hemerythrin both in amino acid sequence (Figure 13) and in secondary, tertiary, and quaternary structure (2).

In general, protein subunits are arranged so as to maximize the ? number of subunit contact points (21). The hemerythrin octamer appears to have a symmetry intermediate between cubic (12 contact points) and square antiprism (16 contact points). However, one kind of contact predominates in the maintenance of the octameric ensemble, giving 4 . strong subunit interactions. A second contact point results in 8 weaker interactions, thus, judging by the criterion of the number of interactions, the stability of octameric hemerythrin is probably closer to that of a cubic structure.

The major contact is a trans interaction between subunits in different planes, subunits related by a twofold axis through the corners of the molecule (Figures 11 and 12). The amino acids responsible for this interaction are located on the $A$ and $B$ helices of different subunits. In this region of the electron density map we found four probable interactions between amino acids in or near the $A$ helix of one subunit with amino acids in the B helix of the other subunits (Figure 12). The important residues in the region of the $\mathrm{A}$ helix are arginine 15 and threonine 19 (prior to the $\mathrm{A}$ helix); and aspartic acid 23 and lysine 26 
(in the $\mathrm{A}$ helix). These interact, respectively, with aspartic acid 42 , arginine 49, lysine 53, and glutamic acid 46 on the $B$ helix. The only co-planar cis interaction for subunits related by the fourfold axis, appears to be a single hydrogen bond involving the peptide backbone carbonyl between residues 66 and 67 in the B to C helix turn and ariginine 48 on the $B$ helix of the adjacent subunit (Figure 11).

Our proposed model for subunit binding (Figure 12) identifies three carboxyl side chains as participating in salt bridges in the trans interactions between subunits. The involvement of ionic bonding in hemerythrin subunit interactions has previously been implicated from studies of the $\mathrm{pH}$ and ionic strength dependence of the dissociation reaction (24). These studies also identified a carboxyl group protonation as being responsible for dissociation at low pH. Further evidence for carboxyl participation comes from studies on $\underline{P}$. gouldii hemerythrin in which it was shown that modification of carboxylates with glycine methyl ester caused the octamer to dissociate (22). Tyrosine modification with tetranitromethane has implicated tyrosine 67 in subunit interactions (23). In our model the carbonyl group preceding residue 67 appears to be responsible for the cis interactions between subunits. An additional substantiation of the proposed model comes from comparing amino acid sequences of the two octameric hemerythrins and monomeric myohemerythrin (from Themiste pyroides) (Figure 13). of the five residue pairs important in subunit interactions, all of the amino acid functional groups are conserved in the octameric hemerythrins, but only one of the pairs is conserved in monomeric hemerythrin. 


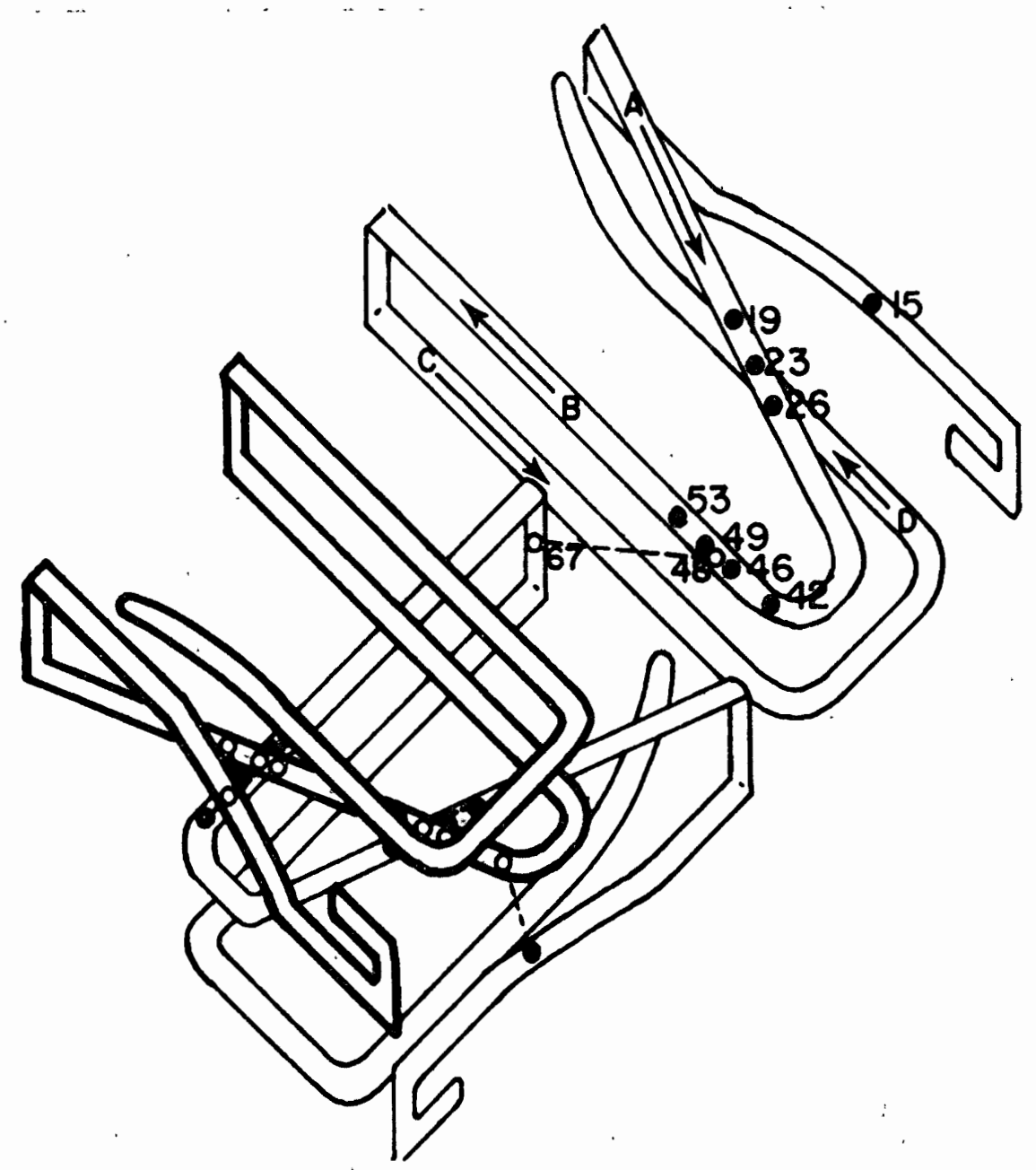

Figure 11: Diagram of $c$ is and trans subunit interaction sites. Figure contains 1 of the 4 subunits in the upper layer (bold face), and 2 of the 4 subunits in the lower layer (light face) of the hemerythrin octamer depicted in Figure 1 . In one subunit the four $\alpha$-helical regions are identified as helices $A, B$, $C$, and D. Arrows indicate direction of polypeptide chain from $\mathrm{NH} 2$-terminal towards COOH-terminal. One cis interaction between arginine 48 and peptide carbonyl 67 is shown for the 2 subunits in the lower layer (light face). Two trans interactions are shown between a subunit in the upper layer and a subunit in the lower layer (at the bottom of the diagram). The amino acid residues responsible for the interaction are indicated by $(0)$ for those extending down from the upper subunit and $(0)$ for those extending upward from the lower subunit. The latter residues are depicted in greater detail on the subunit at the top of the diagram.

Cysteine 50 has long been implicated as being located in a subunitsubunit interface in $\underline{P}$. gouldii hemerythrin, the protein which contains 


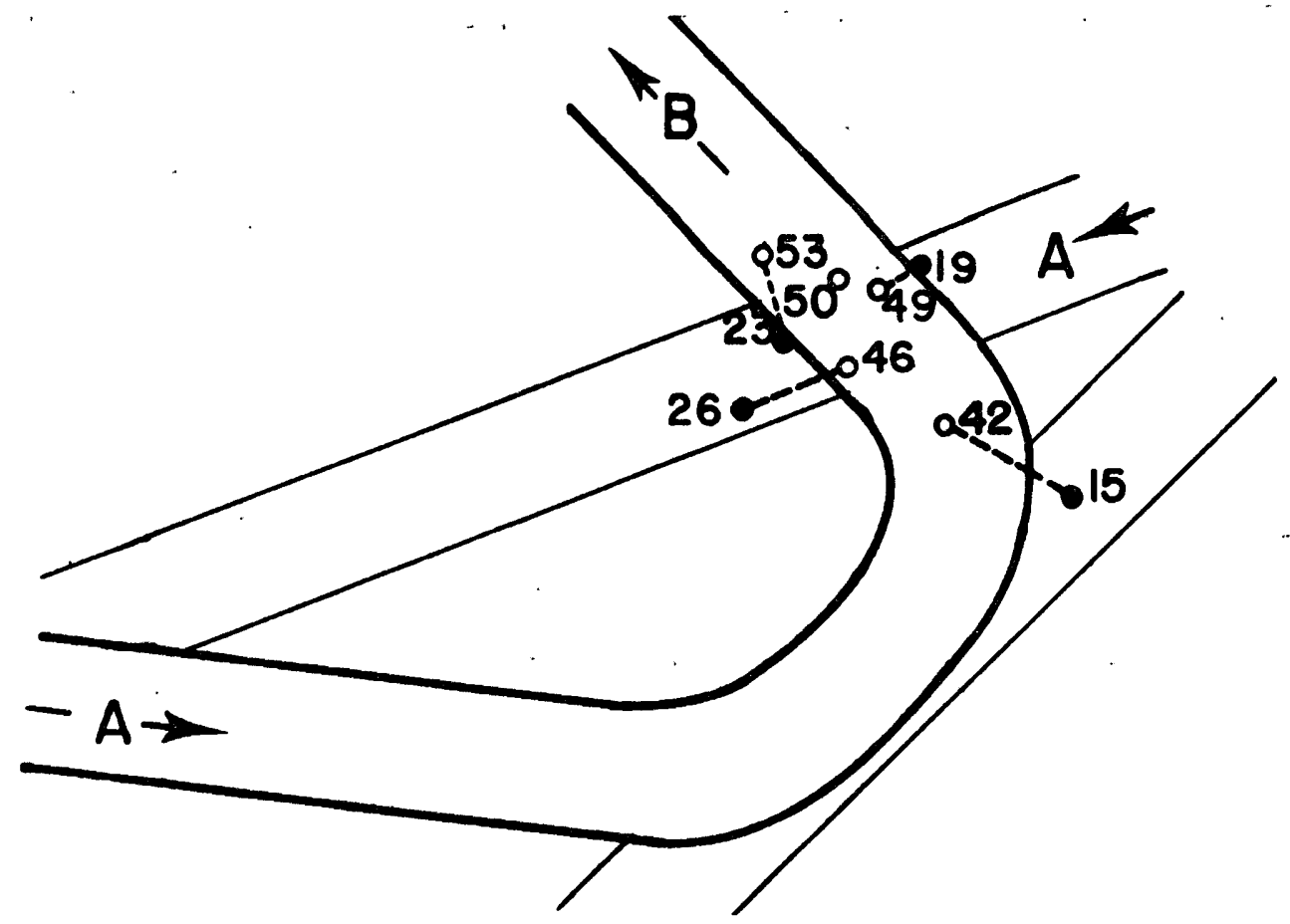

Figure 12. Identification of residues responsible for trans interaction. Enlargement of the right-hand trans region shown in Figure 11. The diagram shows the following interactions:

(o) B helix

(๑) near or in the

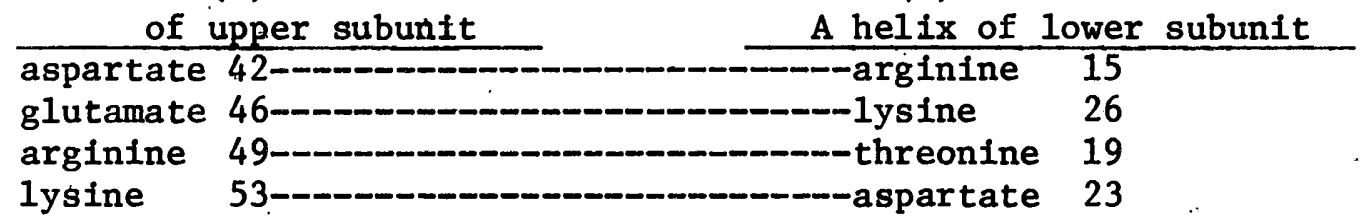

The position of cysteine 50 in the $B$ helix of the upper subunit is also indicated.

only one cysteine residue. When this hemerythrin is treated with sulfhydryl reagents such as PHMB, NEM, or salyrganic acid, there is a linear relationship between the percentage of thiol groups titrated and the percentage dissociation of the macromolecule, complete dissociation being achieved at the stoichiometric equivalence point (3). Modification of cysteines in the octameric protein is directly responsible for dissociation (14). From the electron density maps for $\underline{T}$. dyscritum hemerythrin it can be seen that the cysteine at residue 50 is located 
MYOHEMERYTHRIN (T. pYroldes) COELOHIC HEMERYTHRIN - ( . dyscritum) COELOMIC HEMERYTHRIN ( $\underline{\text { P. gOuldi1) }}$
Gly-Trp-Glu-Ile-Pro-Glu-Pro-Tyr-Val-Trp-Asp-Glu-Ser-Phe-Arg-Val-Phe-Tyr-Glu-Gln Gly-Phe-Pro-Ile-Pro-Asp-Pro-Tyr-Cys-Trp-Asp-Ile-Ser-Phe-Arg-Thr-Phe-Tyr-Thr-Ile Gly-Phe-Pro-Ile-Pro-Asp-Pro-Tyr-Val-Trp-Asp-Pro-Ser-Phe-Arg-Thr-Phe-Tyr-Ser-Ile

Leu-Asp-Glu-Glu-H1s-Lys-Lys-Ile-Phe-Ly8-Gly-Ile-Phe-Cys-Asp-Ile-Arg-Asp-Asn-Ser-Ala-Pro-Asn-Leu-Ala-Thr-Leu-Val-Lys-Va1Val-Asp-Asp-Glu-H1s-Lys-Thr-Leu-Phe-Asn-Gly-Ile-Leu-Leu-Leu-Ser-Gln-Ala-Asp-Asn-Ala-Asp-H1s-Leu-Asn-Glu-Leu-Arg-Arg-CysIle-Asp-Asp-Glu-HIs-Lys-Thr-Leu-Phe-Asn-Gly-Ile-Phe-HIs-Leu-Ala-Ile-Asp-Asp-Asn-Ala-Asp-Asn-Leu-Gly-Glu-Leu-Arg-Arg-Cys-

Thr-Thr-Asn-His-Phe-Thr-HIs-Glu-Glu-Ala-Het-Het-Asp-Ala-Ala-Lys-Tyr-Ser-Glu-Val-Val-Pro-Bis-Lys-Lys-Het-His-Lys-Asp-PheThr-G1 y-Lys-His-Phe-Leu-Asn-Glu-Gln-Gln-Leu-Net-Gln-Ala-Ser-Gln-Tyr-Ala-G1y-Tyr-Ala-Glu-H1s-Lys-Lys-Ala-H1s-Asp-Asp-PheThr-G1y-Lys-His-Phe-Leu-Asn-GIn-Glu-Val-Leu-Het-GIn-Ala-Ser-GIn-Tyr-Gin-Phe-Tyr-Asp-Glu-B1s-Lys-Lys-Glu-H1s-Glu-Gly-Phe-

Leu-Glu-Lys-Ile-Gly-Gly-Leu-Ser-Ala-Pro-Val-Asp-Ala-Lys-Asn-Val-Asp-Tyr-Cys-Lys-Glu-Trp-Leu-Val-Asn-His-Ile-Lys-Giy-ThrIle-HIs-Lys-Leu-Asp-Thr-TrP-Asp-Gly-Asp Ile-HIs-Ala-Leu-Asp-Asn-TrP-Lys-Gly-Asp Va1-Thr-Tyr-Ala-Lys-Asn-Trp-Leu-Val-Asn-H18-Ile-Lys-Thr-IleVal-Lys-Trp-Als-Lys-Ser-Trp-Leu-Va1-Asn-H18-Ile-Lys-Thr-Ile-

\section{0}

Asp-Phe-Lys-Tyr-Lys-Gly-Lys-Leu Asp-Phe-Lys-Tyr-Arg-Gly-Lys-Ile Asp-Phe-Ly8-Tyr-Lys-Gly-Lys-Ile

Figure 13. Comparison of amino acid sequences. Sequence information for T. pyroides myohemerythrin from reference $22 \mathrm{~b}$; for $\mathrm{T}$. dyscritum hemerythrin from reference $\underline{7}$, and for $\underline{P}$. gouldi1 hemerythrin from reference 22c. Black dots denote residues involved in subunit interactions in the octameric form. 
in close proximity to both the cis and trans contact regions (Figures 11 and 12). Thus, it is logical that the introduction of a bulky reagent on cysteine 50 would disrupt the salt bridges and hydrogen bonds holding the subunits together.

Modification of the single cysteine in $\underline{P}$. gouldii hemerythrin caused complete dissociation of the octamer into monomers with no intermediate dissociation products (3). This finding is also well explained by adjacent subunits having only one region of strong subunit interactions. If the subunits in the octameric ensemble were maintained by more than a single major contact point, one would expect to see dissociation products intermediate between octamers and monomers. For example, strong cis interactions between subunits in the same plane would have resulted in the appearance of tetramers upon disruption of the trans interactions by reaction at cysteine 50 .

\section{CHEMICAL MODIFICATION OF CYSTEINE SULFURS}

At the heart of this study lies the information derived from our chemical modification of the two cysteine sulfurs in $\underline{T}$. dyscritum hemerythrin. The comparison of cysteine 50 with cysteine 9 was possible because of access to $\underline{\underline{P}}$. gouldii hemerythrin which is very similar in structure to $\underline{T}$. dyscritum hemerythrin except that it has only a single cysteine at position 50. Thus, the responsibility for dissociation behavior common to both hemerythrins could be attributed to modification of residue 50 , whereas unusual association behavior of $\underline{T}$. dyscritum hemerythrin subunits could be attributed to modification of its cysteine 9.

The sulfhydryl-specific reagents chosen for this study were PHMB, NEM, and mercuric lodide. PHMB is a mercury-containing, thiol-specific 
reagent which is hydrophobic in character, while NEM is an organic, thiol-specific reagent which is hydrophilic (27). As was discussed earlier, the hydrophobicity of mercuric lodide is a function of its coordination number: $\mathrm{HgI}_{2}$ is hydrophobic whereas $\mathrm{HgI}_{3}{ }^{-}$and $\mathrm{HgI}_{4}{ }^{2-}$ are hydrophilic. Characteristic reactions of NEM and PHMB with protein thiol groups are:
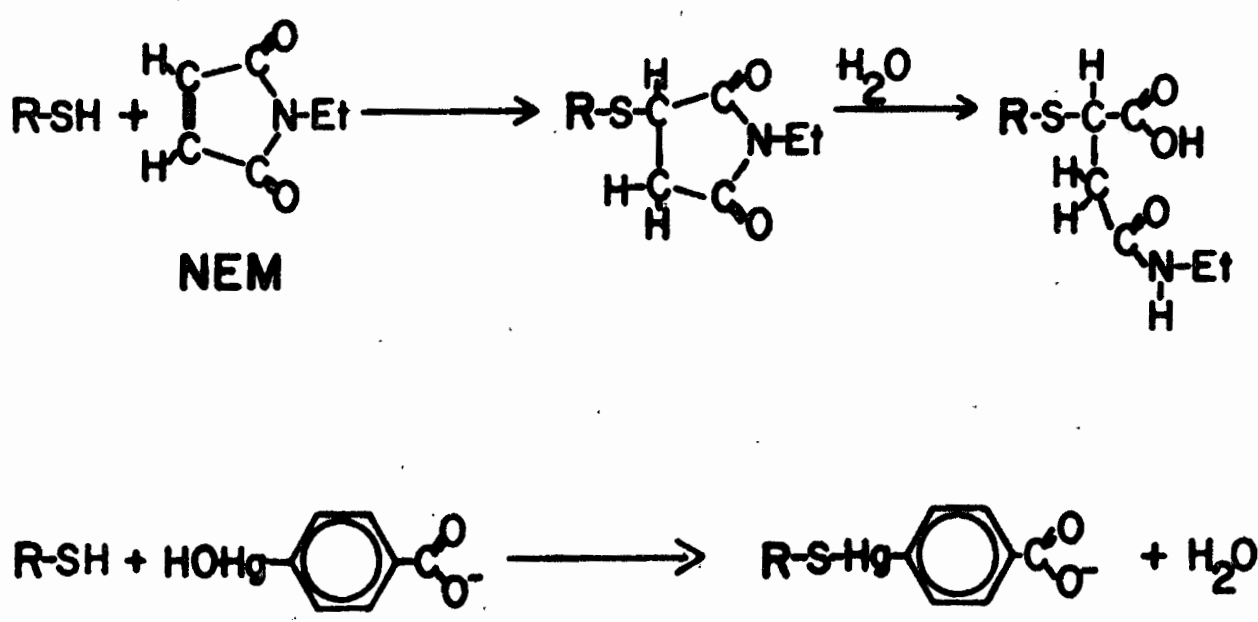

\section{PHMB}

The relative reaction rates of the thiol groups in hemerythrin with PHMB and NEM were investigated in order to gain information about the hydrophobicity of the microenvironments about the cysteines. For NEM, the extent of octamer dissociation and subunit reassociation was used as the sole measure of relative reaction rates, as the reaction is difficult to follow directly. For mercuric lodide, spectrophotometric titration was the only source of relative rate information, as dissociation is negligible:: For PHMB, both methods were used to estimate the relative rates of reaction of different cysteine residues.

Figure 14 outlines the hemerythrin modification reactions used to compare the environment of cysteine 50 with that of cysteine 9. 


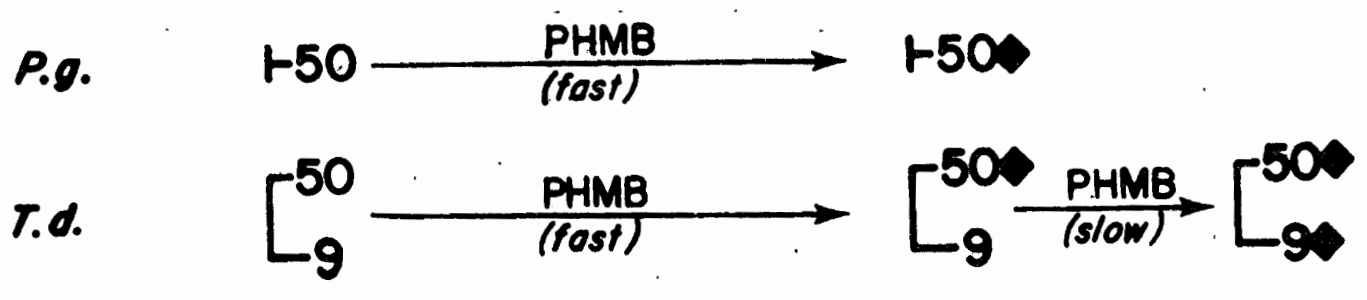

P.g.

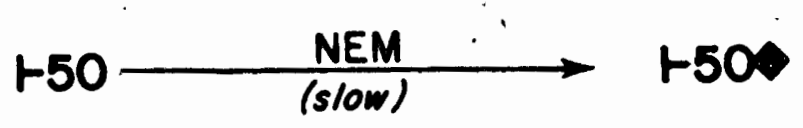

T.d.

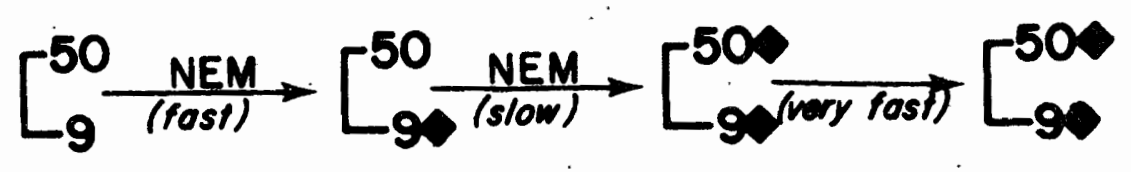

T.d.

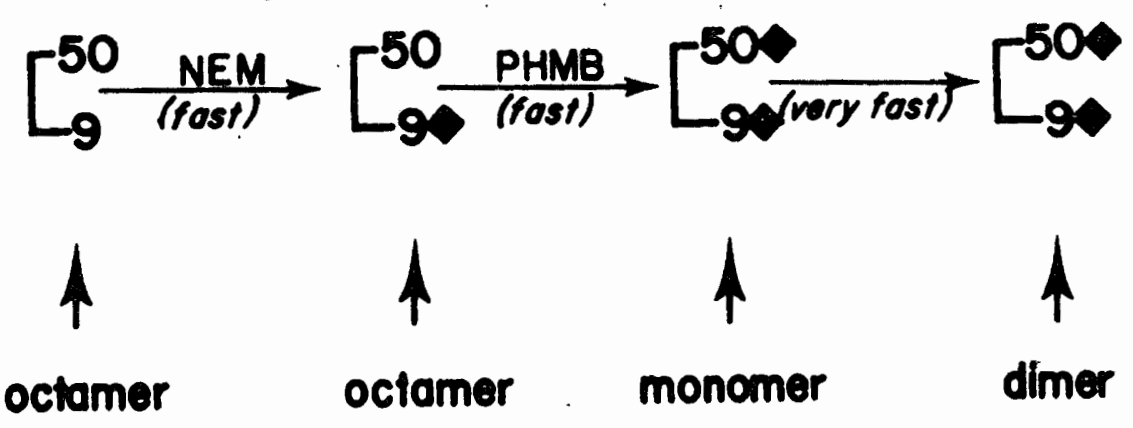

Figure 14. Reaction scheme for the modification of hemerythrins by PHMB and NEM. The numbers refer to the reactive cysteine residues in the hemerythrins from $\underline{P}$. gouldit ( $\underline{P} \cdot g$.$) and \underline{T}$. dyscritum (T.d.). The relative rates are listed below each reaction. The modification of a cysteine residue is indicated by ( ).

As has been reported previously (3), for $\underline{P}$. gouldii hemerythrin monomers are the sole dissociation product resulting from reaction of this protein with PHMB or NEM. Since $\underline{P}$. gouldi1 hemerythrin has a single cysteine at residue 50 , this identifies modification of the cysteine 50 site as the reaction responsible for dissociation. Modification of cysteine 50 also appears to be responsible for the dissociation of $\underline{T}$. dyscritum hemerythrin, as the rate of dissociation with PHMB is similar 


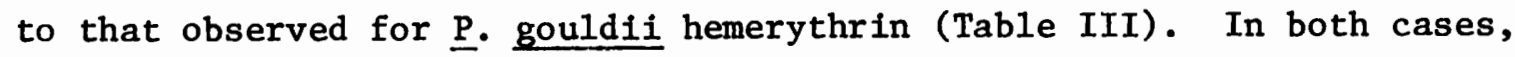
the rate of PHMB-induced dissociation was found to be simflar to the rate of $\mathrm{Hg}-\mathrm{S}$ bond formation $\left(t_{\frac{1}{2}}<1 \mathrm{hr}\right)$ for a single hemerythrin cysteine residue (Figure 3 and reference 14).

The dissociation of $\underline{T}$. dyscritum hemerythrin is complicated by the appearance of association products following dissociation to monomers (Figure 8). However, having assigned the cysteine 50 modification as causing complete dissociation, modification of cysteine 9 must be responsible for association phenomenon observed only with $\underline{T}$. dyscritum hemerythrin.

For both $\underline{\mathrm{p}}$. gouldii and $\underline{\mathrm{T}}$. dyscritum hemerythrin we have shown (Table III, Figure 14) that the cysteine at residue 50 reacts rapidly with PHMB and slowly with NEM. This indicates that cysteine 50 is in a hydrophobic region of the molecule. Further support for this interpretation comes from the $\mathrm{x}$-ray structure which locates cysteine 50 as buried in the interface region between two subunits. However, since at least four of the residues in the vicinity of cysteine 50 are hydophilic in nature (aspartic acid 42, glutamic acid 46, arginine 49, and lysine 53), it is likely that the poor reactivity towards NEM is due to more external hydrophobic residues which block access to this region of the molecule.

The observation that NEM dissociates $\underline{T}$. dyscritum hemerythrin even more slowly than $\underline{p}$. gouldii hemerythrin (Figure 6) could be due to differences in amino acid residues controlling access to cysteine 50. Possible candidates are residues 12 and 34 (Figure 13) located on the outside surface of the molecule. The isoleucine at position 12 and leucine at position 34 in $\underline{T}$. dyscritum hemerythrin are more hydrophobic than the 
proline at position 12 and histidine at position 34 in $\underline{P}$. gouldii hemerythrin.

In contrast to cysteine 50, we observed that cysteine 9 is in a hydrophilic region. PHMB reacts slowly at cysteine 9; whereas NEM reacts rapidly (Figure 14). The conclusion that cysteine 9 is in a hydrophilic region of the molecule is substantiated by $x$-ray diffraction data which shown cysteine 9 to be relatively exposed to the solvent.

Although reaction at cysteine 9 does not itself cause dissociation, it apparently leads to the formation of dimers once the protein has dissociated. To insure that the dimers formed with NEM are the result of NEM modification of cysteine 9, we performed the mixed NEM/PHMB reaction (Figure 14). The protein was first reacted with NEM using conditions which produce no observable dissociation. This was followed by reaction with $\mathrm{PHMB}$ using conditions which lead to monomer formation (i.e. reaction with cysteine 50 ). As the only observed products were dimers, the initial exposure of NEM must have resulted in the modification of the cysteines at position 9.

It is interesting that modification of cysteine 9 in $\underline{T}$. dyscritum hemerythrin produces dimers. As neither NEM nor PHMB is capable of crosslinking the cysteine thiols, the dimerization is 1ikely due to a new subunit interaction. The cysteine 9 lies in an exposed region of the molecule which protrudes slightly into the solvent. It is possible that the addition of a large, negatively-charged group in this region of the molecule enhances electrostatic interactions with other subunit molecules, resulting in dimer formation. This would also explain the anomalous behavior of I. dyscritum hemerythrin towards PHMB. It was found that a 1.5 fold excess of PHMB per subunit, adequate to react only 
half of the cysteine 9 residues, produced complete dimerization. Thus, apparently only one new salt bridge is required for dimer formation.

Dissociation of hemerythrin by sulfhydryl-specific reagents appears to be a function of the bulkiness of the reagent used to modify cysteine 50 . Previous studies on $\underline{P}$. gouldif hemerythrin showed that:large reagents such as NEM, PHMB and salyrganic acid caused dissociation, whereas sma11 molecules such as inorganic mercury and silver caused little or no dissociation (3). In our studies simflar behavior was observed with $\underline{T}$. dyscritum hemerythrin. As discussed previously, the protein thiol group is buried in the subunit interface region, thus the binding of bulky thiol reagents could cause dissociation by mechanically pushing the subunits apart. Inconsistant with this hypothesis, however, is data reported by Kerestez-Nagy and Klotz which showed that P. gouldii hemerythrin was also dissociated by cyanogen bromide which is as small a reagent as $\mathrm{HgI}_{2} \cdot \mathrm{A}$ stolchiometric excess of cyanogen bromide was used in that study, making it possible that the dissociation was due to the modification of other residues in addition to cysteine 50 . An additional species difference between $\underline{P} \cdot \underline{\text { gouldii }}$ and $\underline{T}$. dyscritum hemerythrin is revealed by their dissociation behavior. Although $\underline{P}$ gouldil hemerythrin shows a slight amount of dissociation upon reaction with mercuric iodide, $\underline{T}$. dyscritum hemerythrin shows no dissociation (Table III). The source of $\underline{T}$. dyscritum hemerythrin's added stability may be the mercuric lodide bridge which crosslinks the cysteine 9's on adjacent subunits, thereby mechanically preventing dissociation. 


\section{CONCLUSIONS}

This study was undertaken to determine the manner in which the heavy metal salt, mercuric lodide, binds to the protein, hemerythrin. We found that the mercury is covalently bound to two sulfhydryl groups of cysteine residues. From chemical and spectral studies we showed that the mercury attached to a buried cysteine residue has a linear structure $(-(S)-H g-I)$ while the mercury bridging two exposed cysteine residues has a tetrahedral structure $\left(-(\mathrm{S})_{2} \mathrm{HgI}_{2}\right)$. This appears to be the first example of non-linear mercury bridging and should be of considerable interest to protein crystallographers who regularly use mercuric lodide as a heavy atom derivative.

A second objective of this investigation was to determine the means by which sulfhydry1 reagents cause protein dissociation. Using a $2.8 \AA$ resolution electron density map for hemerythrin, we observed that one of the reactive cysteine residues was in the middle of the major region of subunit interactions which stabilize the octameric form of the protein. This explains the dissociation caused by bulky sulfhydryl reagents such as $\mathrm{p}$-hydroxymercuribenzoate and $\mathrm{N}$-ethylmaleimide. The fact that a smaller reagent such as mercuric lodide can bind without dissociating the protein shows why it is such a good choice for the isomorphous replacement technique in the $x$-ray crystallographic determination of protein structure.

This study has additional implications with regard to the known toxicity of mercury-containing compounds. It is well known that 
inorganic mercury is less toxic than organic mercury. Part of this difference lies in the greater lipid solubility and consequent membrane permeability of organic mercury compounds. However, this present work indicates that an equally important factor may be that inorganic mercury (such as mercuric lodide or mercuric chloride) has a less deleterious effect on protein structure.

It would be interesting to test this hypothesis further by selecting a number of enzymes known to be inhibited by sulfhydryl reagents and comparing the relative inhibitory effects of organic and inorganic mercury compounds. 


\section{REFERENCES}

1. I.M. Klotz, Subunits in Blolog1cal Systems, S.N. Tiniasheff and G.D. Fasman, Eds., M. Dekker, Inc., New York 1971, Vo1. 5, p. 55.

2. I.M. Klotz, G.I. Klippenstein and W.A. Hendrickson, Science, 192, 335 (1976).

3. S. Keresztes-Nagy and I.M. Klotz, Blochemistry, 2, 923 (1963).

4. W.B. Ward, W.A. Hendrickson and G.L. Klippenstein, Nature, 257, 818 (1975).

5. R.G. Stenkamp, L.C. Sieker, L.H. Jensen and J.S. Loehr, J. Mo1. Bio1., 100, 23, (1976).

6. R.E. Stenkamp, L.C. Sieker, and L.H. Jensen, Proc. Nat1. Acad. Sci. U.S.A., $\underline{73}, 349$ (1976).

7. J.S. Loehr, P.J. Lammers, M.A. Hermodson, and B. Brimhall (manuscript in preparation).

8. I.M. Klotz, T.A. Klotz, and H.A. Fiess, Arch. Biochem. Blophys., 68, 284 (1957).

9. S. Keresztes-Nagy and I.M. Klotz, Biochemistry, 4, 919 (1965).

10. J.B.R. Dunn, A.W. Addison, R.E. Bruce, J.S. Loehr and T.M. Loehr, Biochemistry, 16, 1743 (1977).

11. P.D. Boyer, J. Am. Chem. Soc., 76, 4331 (1954).

12. M.H. Klapper, Blochem. Blophys. Res. Commun., 38, 172 (1970).

13. N.J. Taylor and A.J. Carty, J. Amer. Chem. Soc., 19, 6143 (1977).

14. A.L. Rao and S. Keresztes-Nagy, B1ochem. B1ophys. Acta, 304, 575 (1973).

15. T.L. Blundel1 and J.A. Jenkins, Chem. Soc. Rev., 6, 139 (1977).

16. R.G. Pearson, Science, 151, 172 (1966).

17. J.L. Webb, Enzyme and Metabo11c Inhibitors, Academic Press, New York, 1966, Vol. II, p. 730.

18. D. Grdenic, Quart. Rev., (London) 19, 303 (1965).

19. R. Cecil and J.R. McPhee, Adv. In Prot. Chem., 14, 255 (1959).

20. J.A.D. DeWaal and R.G. W11kins, J. Biol. Chem., 251, 2339 (1976). 
21. I.M. Klotz, N.R. Langerman and D.W. Darnall, Ann. Rev. Biochem., 39, 25, (1970).

22. G.L. Klippenstein, Blochem. Biophys. Res. Commun., 49, 1474 (1972).

23. J.L. York and M.P. Roberts, Biochem. Biophys. Acta, 420, 265 (1976).

24. K.H. Tan, S. Keresztes-Nagy, and A. Frankfater, Biochemistry, 14, 4286 (1975).

25. G.L. K1Ippenste1n, J.L. Cote, and S.E. Ludham, Biochemistry, 15, 1128 (1976).

26. G.L. Klippenstein, J.W. Holleman, and I.M. Klotz, Blochemistry, Z, 3868 (1968).

27. G.E. Means and R.E. Feeney, Chemical Modification of Proteins, Holden-Day Inc., San Franc1sco, 1971, p. 19. 